\title{
Crescimento econômico e mudança estrutural no Brasil: um conto de ganhos e perdas
}

\author{
Tomás Amaral Torezani ${ }^{1}$
}

\section{Resumo}

O objetivo desse artigo consiste em identificar, por meio da decomposição de Shapley, a contribuição da produtividade do trabalho, da taxa de emprego e da demografia às variações da renda per capita da economia brasileira de 1950 a 2010. A estratégia empírica utilizada permite avaliar os efeitos das mudanças estruturais e da taxa de emprego sobre o crescimento da renda per capita tanto em termos agregados quanto em termos setoriais. Os resultados agregados encontrados indicam que o crescimento da produtividade foi relevante para o crescimento da renda per capita até 1980 , mas contribuiu negativamente no período pós-1980, momento no qual o componente demográfico se mostrou proeminente. Os resultados setoriais indicaram contribuições importantes da manufatura e dos serviços modernos até 1980, mas negativas posteriormente, enquanto os serviços tradicionais contribuíram positivamente ao longo de todo o período.

\section{Palavras-chave}

Crescimento econômico. Mudança estrutural. Demografia. Decomposição de Shapley. Brasil.

\begin{abstract}
This article aims to identify, through Shapley's decomposition, the contribution of labor productivity, employment rate and demography to changes in the Brazilian economy's per capita income from 1950 to 2010. The empirical strategy used allows evaluating the effects of structural changes and the employment rate on income growth per capita in both aggregate and sectoral terms. The aggregate results indicated that productivity increase was relevant to the income per capita's growth until 1980 , but contributed negatively in the post-1980 period, at which time the demographic component showed prominent. Sectoral results indicated important contributions from manufacturing and modern services until 1980, but negative thereafter, while traditional services contributed positively over the whole period.

- O autor agradece aos participantes do $47^{\circ}$ Encontro Nacional de Economia da ANPEC, realizado em São Paulo em 2019, por comentários à versão inicial deste artigo e, em especial, aos pareceristas anônimos da Revista pelas valiosas contribuições. Eventuais erros remanescentes são de responsabilidade do autor.

1 Analista Pesquisador em Economia - Departamento de Economia e Estatística da Secretaria de Planejamento, Governança e Gestão do Estado do Rio Grande do Sul (DEE/SPGG-RS) - End.: Rua Duque de Caxias, 1691 - Centro Histórico, Porto Alegre - RS - Brasil - CEP: 90010-283. E-mail: tomas torezani@hotmail.com - ORCID: https://orcid.org/0000-0001-9956-3206. Recebido: 15/05/2020. Aceito: 19/08/2021. Editor Responsável: Dante Mendes Aldrighi
\end{abstract}

(c) (i) (\$) Esta obra está licenciada com uma Licença Creative Commons Atribuição-Não Comercial 4.0 Internacional. 


\section{Keywords}

Economic growth. Structural change. Demography. Shapley decomposition. Brazil.

\section{Classificação JEL}

$\mathrm{O} 47, \mathrm{O} 11, \mathrm{~J} 11, \mathrm{~J} 21$

\section{Introdução}

O processo de desenvolvimento econômico pode ser apreendido a partir da dinâmica das atividades econômicas por meio da mudança estrutural de uma economia. A mudança estrutural, entendida como o processo de transformação de ordem qualitativa da estrutura de emprego e de produção de uma economia (rearranjo sequencial da atividade econômica que acompanha o processo de desenvolvimento econômico ao longo de tempo), apresenta-se "não apenas como um subproduto do crescimento, mas como um dos seus principais impulsionadores" (Ocampo et al., 2009, 9). Os padrões de mudança estrutural remontam aos trabalhos seminais de Kuznets (1957), Chenery (1960), Kaldor (1966) e Chenery e Taylor (1968) e vêm sendo amplamente documentados na literatura (Fisher, 1939; Clark, 1940; Kuznets, 1966, 1971; Chenery e Syrquin, 1975; Maddison, 1980; Chenery et al., 1986). ${ }^{1}$

Ainda que o processo de mudança estrutural seja uma característica central do desenvolvimento econômico, seu ritmo e sua direção variam substancialmente de economia para economia. De acordo com Martins (2019), o desenvolvimento econômico requer mudança estrutural, mas, dependendo da direção da realocação dos fatores de produção entre os setores de diferentes níveis de produtividade, esta pode induzir ganhos (growth-enhancing structural change) ou perdas econômicas (growth-reducing structural change). Ademais, a velocidade com que o processo de mudança estrutural ocorre se manifesta como o principal fator de diferenciação entre as trajetórias de crescimento da produtividade e expansão da renda das economias (McMillan e Rodrik, 2011).

1 Para uma compreensiva revisão sobre a literatura que trata da relação entre mudança estrutural, crescimento econômico e produtividade, ver Krüger (2008). Já para um levantamento sobre trabalhos publicados nos últimos 50 anos sobre a temática da mudança estrutural a partir de uma análise bibliométrica, ver Silva e Teixeira (2008). 
Embora grande parte da literatura empírica sobre crescimento econômico tenha se desenvolvido a partir de modelos teóricos neoclássicos sustentados por uma função de produção agregada do tipo Solow-Swan, ${ }^{2}$ houve nos últimos anos um ressurgimento do interesse no estudo que engloba o papel da mudança estrutural no processo de crescimento e desenvolvimento econômico (Temple, 2005; McMillan e Headey, 2014), a partir, por exemplo, de modelos duais de crescimento, assumindo a coexistência de um setor relativamente avançado e outro relativamente atrasado na economia, seja do tipo moderno/tradicional, indústria/agricultura, capitalista/de subsistência, formal/informal, etc. (Caselli, 2005; Temple e Wößmann, 2006; Vollrath, 2009) e de modelos multissetoriais de crescimento (Araújo e Lima, 2007; Araújo, 2013; Gouvea e Lima, 2013). Esses tipos de modelos reconhecem que os gaps de produtividade entre os setores se consubstanciam como uma importante fonte de crescimento econômico (Lewis, 1954). Logo, o desempenho de uma economia dependeria da sua capacidade em promover a mudança estrutural a partir das tendências de realocação de fatores, insumos e produtos de setores menos produtivos para aqueles com maiores dinamismos tecnológico e da demanda (Chenery, 1960; Kuznets, 1966; 1971; Baumol, 1967; Pasinetti, 1993; Imbs e Wacziarg, 2003; Cimoli e Porcile, 2009; Hidalgo e Hausmann, 2009; Ocampo et al., 2009; McMillan e Rodrik, 2011; Duarte e Restuccia, 2010; Herrendorf et al., 2014).

Dado a complexidade do processo de mudança estrutural, o seu significado pode ir além das mudanças na estrutura econômica (da produção e do emprego), pois também abrange mudanças em outros aspectos da sociedade (Kuznets, 1966). Por exemplo, a mudança estrutural pode implicar em mudanças demográficas decorrentes da dinâmica das taxas de fecundidades e de dependência, bem como da distribuição etária da população (McMillan e Headey, 2014; Martins, 2019). Nesse contexto, o presente trabalho utiliza uma estratégia de decomposição que permite uma avaliação empírica que é compatível com uma visão mais ampla da mudança estrutural, avaliando, em termos agregados e em nível setorial, a contribuição da demografia, do emprego e da produtividade do trabalho para o desem-

2 Esses tipos de modelos de apenas um setor forneceram uma base teórica para diversos estudos empíricos que passaram a investigar os determinantes do crescimento econômico tanto por técnicas econométricas quanto por técnicas de contabilidade do crescimento (Barro, 1991; Mankiw et al., 1992). Contudo, a partir dessa agenda de pesquisa, diversos estudos demonstraram que os resultados dos referidos modelos tendem a ser sensíveis à sua especificação, aos dados da amostra e ao método de estimação (Levine e Renelt, 1992; Eberhart e Teal, 2013; Pritchett e Summers, 2014). Essa falta de robustez pode ser, em parte, devido a modelos de um setor não serem capazes de representar a grande heterogeneidade setorial que é uma característica estrutural, sobretudo das economias em desenvolvimento. 
penho da economia brasileira no período 1950-2010, diferentemente da vasta literatura que investiga o papel da mudança estrutural apenas para o crescimento da produtividade. ${ }^{3}$ Assim, o objetivo principal deste trabalho consiste em mensurar, de forma agregada e setorial, os determinantes do crescimento da renda per capita brasileira no período 1950-2010, a partir do papel da produtividade, da taxa de emprego e da demografia por meio da decomposição de Shapley. ${ }^{4}$

Enquanto existem diversos trabalhos na literatura que mensuram o papel dos componentes intrassetorial e mudança estrutural para o crescimento da produtividade do trabalho brasileira a partir de técnicas de shift-share (Bonelli, 2002, 2014; Carvalheiro, 2003; Squeff e De Negri, 2013; Torezani, 2018), raríssimos são os trabalhos que investigam o papel da produtividade, da taxa de emprego e da demografia para o crescimento econômico do país (Bonelli, 2005, 2014; Cavalcante e De Negri, 2014; Torezani, 2018). Entretanto, esses últimos trabalhos apenas investigam as contribuições dos três referidos fatores de forma agregada, não levando em consideração o papel setorial na explicação do crescimento econômico. $\mathrm{O}$ presente artigo se insere na literatura preenchendo essa lacuna ao utilizar uma estratégia de decomposição que engloba uma visão mais ampla da mudança estrutural até então não explorada no estudo da economia brasileira. Nessa perspectiva, a decomposição é feita para investigar o papel da mudança estrutural estática e dinâmica, além do componente intrassetorial, não apenas para o crescimento da produtividade, mas também para o crescimento da renda per capita. ${ }^{5} \mathrm{Na}$ abordagem mais abrangente utilizada

3 A partir de Fabricant (1942), uma extensa literatura utilizando decomposições de contabilidade do crescimento se desenvolveu nos últimos tempos, investigando o papel da mudança estrutural e dos ganhos relativos às produtividades setoriais para o crescimento da produtividade agregada das economias e regiões.

4 É importante já ressaltar que, por se tratar de uma metodologia de contabilidade do crescimento a partir de uma identidade contábil (maiores detalhes na próxima seção), não se pode levar em consideração todos os determinantes do crescimento econômico. A metodologia aqui utilizada é orientada pelo lado da oferta e se concentra nos efeitos de mudanças na distribuição de fatores e insumos específicos (impulsionadas ou não pela evolução do lado da demanda), enquanto que mudanças na demanda são tomadas como exógenas. Essa é uma limitação importante e usual na literatura de crescimento econômico que se utiliza da metodologia shift-share e suas premissas para analisar a mudança estrutural e os determinantes da produtividade, por exemplo (Timmer e Szirmai, 2000). Embora ignore outros tipos de mudanças estruturais que ocorrem em uma economia (mudanças nas taxas de poupança e investimento, urbanização, mudanças na desigualdade de renda, na cultura e nas instituições, etc.), de Vries et al. (2015) indicam que a referida abordagem direciona o foco do processo de mudança estrutural para a questão produtiva, permitindo estudar detalhadamente várias características relevantes de uma economia.

5 Como indicado anteriormente, os trabalhos que tratam da questão da mudança estrutural apenas investigam os seus efeitos no crescimento da produtividade. Entretanto, a produtividade é apenas um dos principais fatores determinantes do crescimento econômico. 
neste trabalho, mensura-se, além do papel da produtividade para o crescimento econômico do Brasil, o do componente demográfico e da taxa de emprego, tanto no aspecto agregado quanto nas contribuições setoriais de cada componente. Ademais, outra contribuição do trabalho refere-se ao método de decomposição empregado. Também até onde se sabe, a decomposição de Shapley ainda não foi utilizada para a avaliação da dinâmica da economia brasileira.

Para alcançar o objetivo proposto, o artigo está estruturado da seguinte forma, além desta introdução: a seção 2 descreve a metodologia de decomposição utilizada; a seção 3 expõe a base de dados; a seção 4 apresenta uma visão geral da heterogeneidade produtiva da economia brasileira e o seu padrão de mudança estrutural; a seção 5 exibe e discute os resultados das decomposições; por fim, a última seção remete-se às considerações finais.

\section{Metodologia}

O objetivo dessa seção é apresentar a metodologia que permite compreender e mensurar as contribuições de fatores relevantes para o crescimento econômico, enfatizando como os padrões de crescimento setoriais de tais fatores afetam o crescimento agregado, a partir da decomposição de Shapley. ${ }^{6}$ Nesse sentido, o ponto de partida consiste em identificar a renda per capita $(y)$ a partir de três fatores:

$$
\begin{aligned}
& \frac{Y}{N}=\frac{Y}{E} \cdot \frac{E}{A} \cdot \frac{A}{N} \\
& y=p \cdot e \cdot a
\end{aligned}
$$

6 A presente seção baseia-se na metodologia proposta por World Bank (2012). A decomposição de Shapley, proposta por Shorrocks (2013), é bastante difundida na literatura econômica para decompor indicadores de pobreza e desigualdade, mas ainda praticamente inexplorada no estudo de crescimento econômico, sobretudo no Brasil. Segundo Shorrocks (2013), a decomposição de Shapley consiste em um método geral de avaliação das contribuições de um conjunto de fatores que conjuntamente respondem pelo valor observado de alguma estatística agregada. Por conta de a fórmula resultante ser formalmente idêntica ao valor de Shapley (Shapley, 1953) dentro da teoria dos jogos cooperativos, tal decomposição passou a ser referida como "decomposição de Shapley". 
onde $Y$ é o produto, $N$ a população total, $E$ o emprego total e $A$ a população em idade ativa (PIA) ${ }^{7}$ Dessa forma, $p$ expressa a produtividade do trabalho (produto por trabalhador) ${ }^{8} e$ a taxa de emprego ${ }^{9}$ e $a$ um componente demográfico que captura uma mudança demográfica ${ }^{10}$ Assim, o crescimento da renda per capita pode ser decomposto nos crescimentos associados a mudanças na produtividade do trabalho, na taxa de emprego e no componente demográfico. A partir do método de decomposição de Shapley, o qual é inerentemente aditivo, a mudança total na renda per capita será a soma do crescimento atribuído para cada um de seus componentes. Identificando $\bar{p}, \bar{e}$ e $\bar{a}$ como a fração de crescimento ligada a cada componente, o aumento total da renda per capita de uma economia $\left(\Delta y=y_{t=1}-y_{t=0}\right)$ pode ser expresso como:

$$
\Delta y=\bar{p} \cdot \Delta y+\bar{e} \cdot \Delta y+\bar{a} \cdot \Delta y
$$

ou em forma de taxa de crescimento:

$$
\bar{y}=\frac{\Delta y}{y}=\bar{p} \cdot \frac{\Delta y}{y}+\bar{e} \cdot \frac{\Delta y}{y}+\bar{a} \cdot \frac{\Delta y}{y}
$$

onde $(\bar{p} \cdot \Delta y)$ refletirá a quantidade de crescimento que seria consistente com um cenário em que a produtividade tivesse mudado conforme observado, mas a taxa de emprego $(e)$ e a parcela da população em idade para trabalhar na população total $(a)$ "permanecessem constantes". Da mes-

7 Considera-se a população entre 15 e 64 anos.

8 A produtividade do trabalho é uma variável que indica a eficiência produtiva da economia e é um dos principais determinantes do crescimento de longo prazo. Ao longo do texto, quando não especificado, usa-se "produtividade" e "produtividade do trabalho" como sinônimos.

9 A rigor, a taxa de emprego refere-se à razão entre o número de pessoal ocupado e a população que efetivamente participa do mercado de trabalho, isto é, aquelas pessoas que estão empregadas ou procurando emprego (população economicamente ativa, PEA). Entretanto, aqui se nomeia "taxa de emprego" como a razão entre o pessoal ocupado e a PIA (15 a 64 anos), sobretudo pela dificuldade de se encontrar séries históricas longas consistentes de PEA. Ademais, seguindo diversos trabalhos na literatura, a definição de PEA em países de baixa e média renda pode ser muito difícil de medir, pois, em muitos casos, a desocupação em um país pode ser baixa por não estarem incluídos, por exemplo, agentes desempregados sazonalmente e trabalhadores desalentados. Nesses casos, uma melhor medida da força de trabalho seria a PIA ao invés da PEA. Nesse sentido, os resultados da decomposição do que aqui é chamado de "taxa de emprego" podem estar subestimados dado que a PEA está contida na PIA.

${ }^{10}$ Embora mudanças demográficas possam ter efeitos significativos no crescimento econômico de um país, o referido componente da decomposição realizada não captura todas as mudanças demográficas. Ele, em realidade, consegue indicar o bônus demográfico (no caso de uma taxa positiva de crescimento da razão entre a PIA e a população total) ou o ônus demográfico (taxa negativa), o que também se mostra relevante para se compreender com maior propriedade a transição demográfica e seu efeito no crescimento econômico. 
ma forma, $\bar{e} \cdot \Delta y$ será a quantidade de crescimento consistente com um cenário no qual a produtividade e a parcela da população em idade ativa "permanecessem constantes". Por seu turno, $(\bar{a} \cdot \Delta y)$ será a quantidade do crescimento da renda per capita explicado pelo componente demográfico.

Existem várias maneiras pelas quais os dois componentes de cada caso podem "permanecer constantes": (i) ambos podem permanecer no nível observado no ano inicial; (ii) ambos podem permanecer no nível observado no último ano; ou (iii) um deles pode permanecer no nível observado no ano inicial e o outro permanecer no nível observado no ano final. A escolha por qual dos tratamentos possíveis dependerá da abordagem de decomposição a ser seguida, ou seja, da suposição em relação ao ano base dos componentes. Os métodos de decomposição mais utilizados na literatura consideram apenas o caso em que ambos os componentes permanecem no nível observado no ano inicial ou no ano final (ou mesmo com uma média dos dois casos) e, assim, terminam com um residual. Por outro lado, a decomposição de Shapley considera todas as alternativas possíveis e, em seguida, computa uma média ponderada de cada uma delas, com os pesos refletindo o número de maneiras que cada componente pode permanecer inalterado. Dessa forma, elimina-se o componente residual, que dependendo do caso pode ser muito grande. Cada componente, portanto, tem a interpretação de um cenário contrafactual. Logo, a abordagem da decomposição de Shapley baseia-se no efeito marginal sobre o valor de uma variável a partir da eliminação da mudança de cada um dos seus fatores contributivos em uma sequência. $\mathrm{O}$ método atribui a cada fator a média de sua contribuição marginal em todas as sequências de eliminação possíveis. ${ }^{11}$

Aplicando a decomposição de Shapley à equação 3, tem-se que:

$$
\begin{aligned}
& \bar{p}=\Delta p\left[\frac{1}{3}\left(e_{t=1} a_{t=1}+e_{t=0} a_{t=0}\right)+\frac{1}{6}\left(e_{t=1} a_{t=0}+e_{t=0} a_{t=1}\right)\right] / \Delta y \\
& \bar{e}=\Delta e\left[\frac{1}{3}\left(p_{t=1} a_{t=1}+p_{t=0} a_{t=0}\right)+\frac{1}{6}\left(p_{t=1} a_{t=0}+p_{t=0} a_{t=1}\right)\right] / \Delta y \\
& \bar{a}=\Delta a\left[\frac{1}{3}\left(p_{t=1} e_{t=1}+p_{t=0} e_{t=0}\right)+\frac{1}{6}\left(p_{t=1} e_{t=0}+p_{t=0} e_{t=1}\right)\right] / \Delta y
\end{aligned}
$$

${ }^{11}$ Para maiores detalhes, ver Shorrocks (2013). 
onde cada um dos termos representam as contribuições de mudanças na produtividade do trabalho, na taxa de emprego e no componente demográfico para o crescimento da renda per capita.

Para além da decomposição em termos agregados, as contribuições da produtividade e da taxa de emprego para o crescimento da renda per capita podem ser estendidas para o nível setorial. No caso da taxa de emprego agregada $(e)$, o seu crescimento total $(\Delta e)$ pode ser expresso como:

$$
\Delta e=\sum_{i=1}^{n} \Delta \frac{E_{i}}{A}=\sum_{i=1}^{n} \Delta e_{i}
$$

onde $\Delta e_{i}$ representa a mudança no emprego do setor $i$ em relação à participação da PIA. Dividindo ambos os lados da equação por $e$, captura-se a fração da variação agregada da taxa de emprego que pode ser atribuída a mudanças no emprego do setor $i$. Já a contribuição do emprego do setor $i$ para a variação da renda per capita $\left(\bar{e}_{i}\right)$ será sua contribuição a mudanças no emprego total $\left(\bar{e}_{i}^{e}\right)$ multiplicada pela contribuição da variação da taxa de emprego agregada no crescimento da renda per capita $(\bar{e})$ :

$$
\overline{e_{i}}=\overline{e_{i}^{e}} \cdot \bar{e}=\left(\frac{\Delta e_{i}}{\Delta e}\right) \bar{e}
$$

Da mesma forma como já assinalado anteriormente, isso pode ser interpretado como o crescimento da renda per capita consistente com um cenário contrafactual, no qual todos os seus demais fatores (produtividade, demografia e emprego nos demais setores) permanecem inalterados e a única mudança é o crescimento do emprego observado no setor $i$.

Por seu turno, a produtividade agregada $(p)$ pode ser apreendida como o somatório das produtividades setoriais $\left(p_{i}\right)$ ponderadas pela participação de cada setor no total de empregos da economia $\left(s_{i}\right)$ :

$$
p=\frac{Y}{E}=\sum_{i=1}^{n} \frac{Y_{i}}{E_{i}}=\sum_{i=1}^{n}\left(\frac{Y_{i}}{E_{i}} \frac{E_{i}}{E}\right)=\sum_{i=1}^{n} p_{i} s_{i}
$$

Usando o método de Shapley, é possível decompor a variação da produtividade agregada em dois componentes: 


$$
\Delta p=\Delta p_{w}+\Delta p_{b}=\left[\sum_{i=1}^{n} \Delta p_{i}\left(\frac{s_{i, t=o}+s_{i, t=1}}{2}\right)\right]+\left[\sum_{i=1}^{n} \Delta s_{i}\left(\frac{p_{i, t=o}+p_{i, t=1}}{2}\right)\right]
$$

onde $\Delta p_{w}$ mede os efeitos da produtividade intrassetorial (within effect) ${ }^{12}$, enquanto $\Delta p_{b}$ mede os efeitos da realocação de emprego entre os setores (between effect), sendo comumente conhecido na literatura como efeito 'mudança estrutural'.

Aumentos na produtividade de um setor aumentará a produtividade média da economia e a magnitude de seu efeito dependerá do peso desse setor na economia em termos de emprego. Já a realocação de trabalhadores entre os setores de diferentes níveis de produtividade pode aumentar a produtividade média se a realocação final ocorrer em setores com maiores níveis de produtividade ou diminuir se o fator trabalho estiver migrando para setores menos produtivos. Em suma, enquanto o primeiro efeito captura o crescimento da produtividade de cada um dos setores da economia (em função de fatores intrínsecos a cada setor como, por exemplo, alterações na relação capital-trabalho e mudanças tecnológicas), o segundo mede a realocação do trabalho entre os diferentes setores.

As contribuições de cada um dos componentes do crescimento da produtividade para o crescimento da renda per capita podem ser obtidos a partir das seguintes expressões:

$$
\begin{aligned}
& \overline{p_{w}}=\overline{p_{w}^{p}} \cdot \bar{p}=\left\{\left[\sum_{i=1}^{n} \Delta p_{i}\left(\frac{s_{i, t=o}+s_{i, t=1}}{2}\right)\right] / \Delta p\right\} \cdot \bar{p} \\
& \overline{p_{b}}=\overline{p_{b}^{p}} \cdot \bar{p}=\left\{\left[\sum_{i=1}^{n} \Delta s_{i}\left(\frac{p_{i, t=o}+p_{i, t=1}}{2}\right)\right] / \Delta p\right\} \cdot \bar{p}
\end{aligned}
$$

Novamente, segue-se a interpretação contrafactual: por exemplo, a contribuição de mudanças na produtividade intrassetorial pode ser interpretada como o total do crescimento per capita consistente com um cenário contrafactual, no qual todo o resto permanece constante (taxa de emprego, componente demográfico e produtividade nos demais setores) e a única alteração observada é a mudança na produtividade do setor $i$.

\footnotetext{
${ }^{12}$ Nos resultados agregados, utiliza-se o termo "componente intrassetorial". Já nos resultados setoriais, a contribuição de cada uma das atividades é identificada com o termo "componente setorial".
} 
Ainda é possível decompor o efeito intrassetorial (primeiro termo da equação 11) em dois componentes: mudanças na tecnologia (produtividade total dos fatores) e na relação capital-trabalho. Assumindo retornos constantes de escala, se $Y=\phi f(K, E)$, onde $K$ é o estoque de capital e $\phi$ um parâmetro de mudança multiplicativo, então o produto por trabalhador (produtividade do trabalho) será $Y / E=\phi f(1, K / E)$ e capturará mudanças na relação capital-trabalho $(K / E=k)$ e mudanças no parâmetro $\phi$. As mudanças no referido parâmetro captarão todas as outras fontes de crescimento que não as capturadas por mudanças na relação capital-trabalho, ou seja, o chamado resíduo de Solow. Ele captará principalmente mudanças na tecnologia e na realocação da produção entre setores com diferentes níveis de produtividade (mudanças intersetoriais).

Isolando o efeito de mudanças intersetoriais (between effect), é possível decompor mudanças na produtividade intrassetorial (within effect) em mudanças devidas aos aumentos da relação capital-trabalho e do resíduo, o qual pode ser interpretado, com cautela, como crescimento da produtividade total dos fatores (TFP). Assumindo uma função de produção do tipo Cobb-Douglas onde $\alpha$ representa a parcela salarial na renda e $(1-\alpha)$ a parcela do capital, então:

$$
\frac{Y}{E}=\phi\left(\frac{K}{E}\right)^{1-\alpha}
$$

Calculando a TFP como um resíduo, no primeiro período $(t=0)$ tem-se que:

$$
\phi_{t=0}=T F P_{t=0}=\left(\frac{Y}{E}\right)_{t=0} /\left(\frac{K}{E}\right)_{t=0}^{1-\alpha}
$$

Já para o segundo período $(t=1)$, é necessário levar em consideração que parte da mudança na produtividade agregada se deve ao efeito realocação $\left(\Delta p_{b}\right), \log$ :

$$
\phi_{t=1}=T F P_{t=1}=\left[\left(\frac{Y}{E}\right)_{t=1}-\Delta p_{b}\right] /\left(\frac{K}{E}\right)_{t=1}^{1-\alpha}
$$

Assim sendo, é possível identificar se mudanças na produtividade líquidas do efeito realocação $\left(Y / E-\Delta p_{b}=\Delta p_{w}\right)$ se devem a aumentos/reduções na 
relação capital-trabalho (primeiro termo do lado direito da equação abaixo) ou na produtividade total dos fatores (segundo termo da equação):

$$
\Delta p_{w}=\left[\Delta k^{1-\alpha} \cdot\left(\frac{T F P_{t=0}+T F P_{t=1}}{2}\right)\right]+\left[\Delta T F P \cdot\left(\frac{k_{t=0}^{1-\alpha}+k_{t=1}^{1-\alpha}}{2}\right)\right]
$$

Já as contribuições de cada um dos termos para o crescimento da renda per capita podem ser expressas como:

$$
\begin{aligned}
& \overline{T F P}=\overline{T F P^{p}} \cdot \overline{p_{w}}=\left[\Delta T F P\left(\frac{k_{t=0}^{1-\alpha}+k_{t=1}^{1-\alpha}}{2}\right) / \Delta p\right] \cdot \overline{p_{w}} \\
& \bar{k}=\overline{k^{p}} \cdot \overline{p_{w}}=\left[\Delta k^{1-\alpha}\left(\frac{T F P_{t=o}+T F P_{t=1}}{2}\right) / \Delta p\right] \cdot \overline{p_{w}}
\end{aligned}
$$

Por fim, assim como o componente intrassetorial do crescimento da produtividade, também é possível decompor o componente 'mudança estrutural' (segundo componente da equação 11) em dois fatores, quais sejam, a 'mudança estrutural estática' e a 'mudança estrutural dinâmica'. ${ }^{13}$ A 'mudança estrutural estática' mede se o trabalho está se movendo para atividades com níveis de produtividade acima da média, isto é, mede a capacidade de uma economia realocar trabalho de atividades com baixa produtividade para outras com níveis mais elevados de produtividade no período inicial. Já 'mudança estrutural dinâmica' representa o efeito conjunto de mudanças nas produtividades setoriais e de mudanças na alocação de trabalho entre as atividades. Tal efeito será positivo se as atividades com maiores crescimentos da produtividade também aumentam sua participação no emprego total, refletindo, dessa forma, a capacidade de uma economia em realocar seus recursos em direção a atividades mais dinâmicas, ou seja, aquelas com maiores taxas de crescimento da produtividade do trabalho.

A Figura 1 expõe a representação da abordagem utilizada no presente trabalho.

${ }^{13}$ A decomposição do crescimento da produtividade é bastante comum na literatura de crescimento econômico, mas não são todos os trabalhos que desagregam a mudança estrutural nos seus componentes estático e dinâmico (de Vries et al., 2015). Entretanto, mesmos os estudos que mensuram a mudança estrutural em suas duas dimensões, o fazem apenas para o crescimento da produtividade. Já o presente trabalho, assim como o estudo de Haile (2018) para três países africanos, amplia o escopo da decomposição, também mensurando o papel da mudança estrutural para o crescimento da renda per capita. 


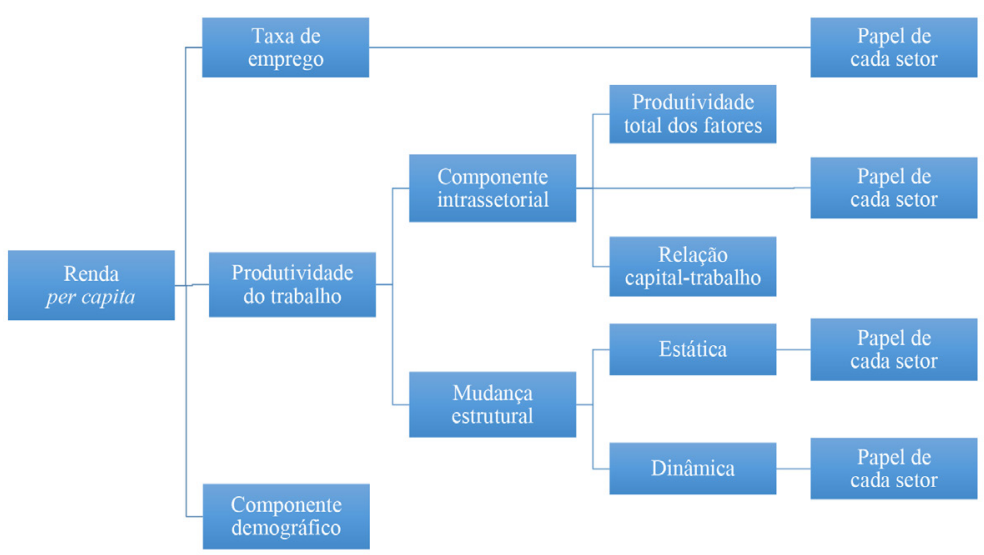

Figura 1 - Abordagem da decomposição utilizada no trabalho

Fonte: Elaboração própria a partir de World Bank (2012).

\section{Base de dados}

Os dados setoriais de valor adicionado e emprego são provenientes da GGDC 10-Sector Database, a qual disponibiliza os referidos dados em uma desagregação de 10 setores exposta na Tabela 1 .

Tabela 1 - Atividades econômicas da GGDC 10-Sector Database

\begin{tabular}{|c|c|c|c|}
\hline ISIC Rev. 3.1 & Abreviação & Nome da atividade & Descrição da atividade \\
\hline$A+B$ & agr & Agropecuária & Agricultura; Caça; Silvicultura; Pesca \\
\hline C & $\min$ & Indústria extrativa & Indústria extrativa \\
\hline D & $\operatorname{man}$ & Manufatura & Indústria de transformação \\
\hline $\mathrm{E}$ & $\mathrm{pu}$ & Utilidades públicas & Eletricidade; Gás; Fornecimento de água \\
\hline $\mathrm{F}$ & cons & Construção & Construção \\
\hline $\mathrm{G}+\mathrm{H}$ & trh & Serviços comerciais & $\begin{array}{l}\text { Comércio atacadista e varejista; Reparação de veículos, motocicle- } \\
\text { tas e bens de uso pessoal; Hotéis e restaurantes }\end{array}$ \\
\hline I & tsc & Serviços de transporte & Transporte, Armazenamento, Comunicações \\
\hline $\mathrm{J}+\mathrm{K}$ & fire & $\begin{array}{l}\text { Serviços } \\
\text { empresariais }\end{array}$ & $\begin{array}{l}\text { Intermediação financeira; Aluguel; Atividades empresariais (ex- } \\
\text { cluindo aluguéis ocupados pelo proprietário) }\end{array}$ \\
\hline $\mathrm{L}+\mathrm{M}+\mathrm{N}$ & gs & $\begin{array}{c}\text { Serviços } \\
\text { governamentais }\end{array}$ & Administração pública; Defesa; Educação; Saúde; Serviços sociais \\
\hline $\mathrm{O}+\mathrm{P}$ & csps & Serviços pessoais & Serviços comunitários, sociais e pessoais; Atividades das famílias \\
\hline TOTAL & tot & Total da economia & Total da economia \\
\hline
\end{tabular}

Fonte: Groningen Growth and Development Center (GGDC). 
Por seu turno, os dados relativos à população total e à PIA (15 a 64 anos) são provenientes da World Population Prospects, revisão 2017, da Organização das Nações Unidas (ONU). O estoque de capital é oriundo da Penn World Table 8.1. Já a série da parcela salarial na renda da economia brasileira foi estimada com dados da Fundação Getúlio Vargas (FGV) e do Instituto Brasileiro de Geografia e Estatística (IBGE) de acordo com a correção proposta por Gollin (2002), separando os rendimentos mistos entre remuneração do trabalho e do capital, além de também separar a remuneração agrícola entre salários e excedente operacional bruto. Todos os valores monetários estão em reais (R\$) a preços constantes de 2005. O período considerado no trabalho compreende os anos de 1950 a 2010.

\section{Visão panorâmica dos gaps de produtividade e da mudança estrutural}

O crescimento econômico neste trabalho é mensurado pela renda per capita, expressa pela razão entre o valor adicionado e a população, através de dados do GGDC e da ONU e ao longo do período 1950-2010. O Gráfico 1 apresenta, além da média decenal de crescimento da referida variável, as taxas de crescimento anual e decenal do PIB e do PIB per capita no período 1901-2018 (dados do Sistema de Contas Nacionais-IBGE e Haddad, 1980). Como se pode observar, os comportamentos da renda per capita e do PIB per capita são bastante sincronizados, apenas com certa discrepância nos anos $1990 .^{14}$

${ }^{14}$ Ressalta-se que além de questões metodológicas das fontes de dados em questão (GGDC e ONU) em relação aos dados do IBGE, as divergências também são resultado da utilização do valor adicionado na renda per capita e do PIB no PIB per capita. 


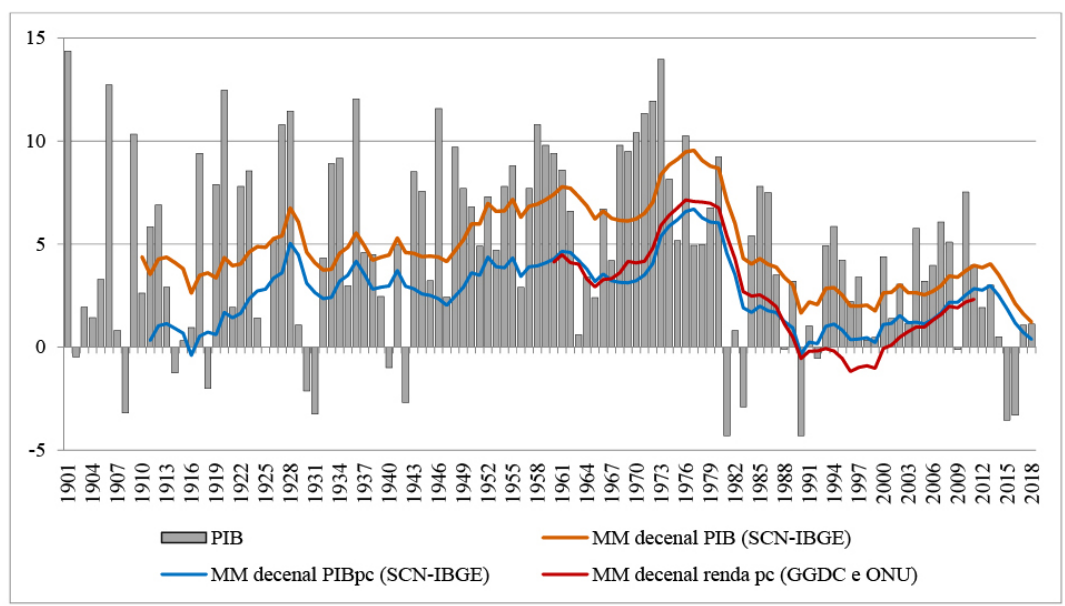

Gráfico 1 - Crescimento anual e decenal do PIB, do PIB per capita da economia brasileira, 1901-2018 (\%)

Fonte: Elaboração própria com dados do Sistema de Contas Nacionais-IBGE e Haddad (1980).

Notas: MM refere-se à média móvel. Renda per capita refere-se à razão entre o valor adicionado (GGDC) e a população (ONU).

Por seu turno, o Gráfico 2 expõe a evolução do nível da renda per capita ao longo do período 1950-2010. Como fica evidenciado, existe uma clara distinção entre a dinâmica do subperíodo 1950-80 (crescimento acelerado e robusto) e o subperíodo posterior (semi-estagnação). Tal distinção, para além da renda per capita, também pode ser constatada pela Tabela 2, a qual traz informações de outras variáveis relevantes na investigação do presente trabalho.

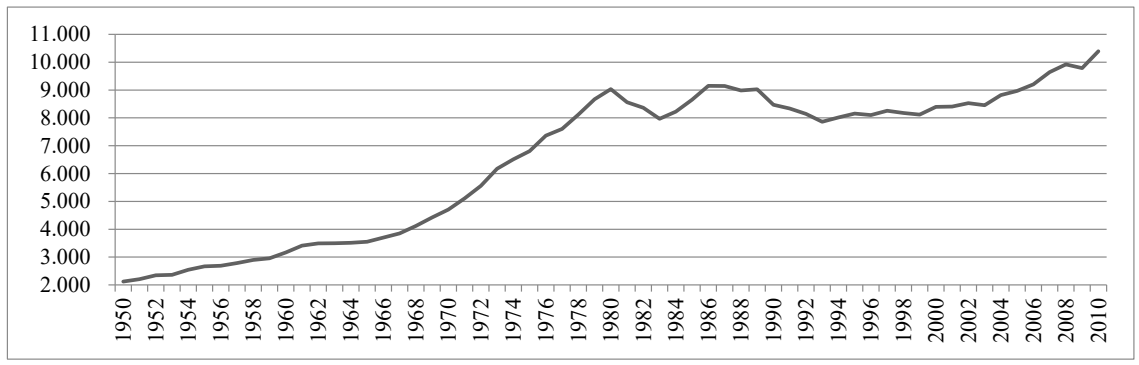

Gráfico 2 - Evolução da renda per capita da economia brasileira, 1950-2010 (R\$ mil de 2005)

Fonte: Elaboração própria com dados de GGDC e ONU. 
Tabela 2 - Nível e crescimento de variáveis selecionadas, diversos períodos

\begin{tabular}{lcccccccc}
\hline & \multicolumn{3}{c}{ Vivel } & & \multicolumn{3}{c}{ Crescimento anualizado } \\
\cline { 2 - 5 } \cline { 8 - 9 } & 1950 & 1980 & 2010 & & $1950-1980$ & $1980-2010$ & $1950-2010$ \\
\hline Valor adicionado & 114 & 1.094 & 2.046 & & $7,8 \%$ & $2,1 \%$ & $4,9 \%$ \\
População (milhões pessoas) & 54 & 121 & 197 & & $2,7 \%$ & $1,6 \%$ & $2,2 \%$ \\
PIA (milhões de pessoas, 15 a 64 anos) & 30 & 70 & 135 & & $2,9 \%$ & $2,2 \%$ & $2,5 \%$ \\
Empregados (milhões de pessoas) & 20 & 50 & 101 & & $3,2 \%$ & $2,4 \%$ & $2,8 \%$ \\
Renda per capita (R\$ mil 2005/pessoa) & 2.119 & 9.032 & 10.396 & & $5,0 \%$ & $0,5 \%$ & $2,7 \%$ \\
Produtividade (R\$ mil 2005/empregado) & 5.826 & 21.860 & 20.346 & & $4,5 \%$ & $-0,2 \%$ & $2,1 \%$ \\
Taxa de emprego (EMP/PIA) & $66 \%$ & $71 \%$ & $75 \%$ & & $0,3 \%$ & $0,2 \%$ & $0,2 \%$ \\
Estrutura etária (PIA/POP) & $55 \%$ & $58 \%$ & $68 \%$ & & $0,1 \%$ & $0,6 \%$ & $0,3 \%$ \\
\hline
\end{tabular}

Fonte: Elaboração própria com dados de GGDC e ONU.

Após um panorama dos dados agregados, faz-se pertinente investigar o papel da produtividade e da mudança estrutural em termos setoriais. $\mathrm{O}$ Gráfico 3 expõe a produtividade relativa (produtividade setorial em relação à produtividade total $)^{15}$ e a participação no emprego total de cada uma das dez atividades econômicas em quatro momentos do tempo, de forma que a área de cada uma das barras representa a proporção do valor adicionado em relação ao emprego total, fornecendo uma rica ilustração do tamanho relativo (em termos de emprego) e do nível de produtividade de cada atividade. Como é possível observar, as diferenças intersetoriais de produtividade da economia brasileira indicam a evolução ao longo do tempo da heterogeneidade estrutural do país (coexistência de atividades com níveis de produtividade bastante diferentes). Ademais, as atividades de alta produtividade sempre empregaram uma parcela insignificante da força de trabalho, enquanto as atividades de baixa produtividade e aquelas em rápida expansão mantiveram uma produtividade muito baixa e absorveram grande parte do emprego produtivo, sobretudo a força de trabalho que saiu da agropecuária. Nesse sentido, entende-se que a heterogeneidade no Brasil é estrutural e persistente.

\footnotetext{
${ }^{15}$ Valores superiores à unidade indicam níveis de produtividade maiores que a produtividade agregada da economia.
} 


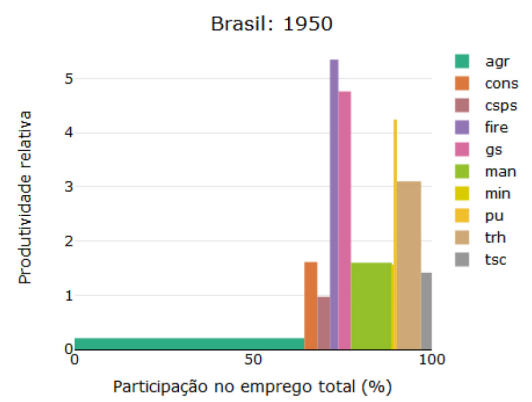

Brasil: 1990

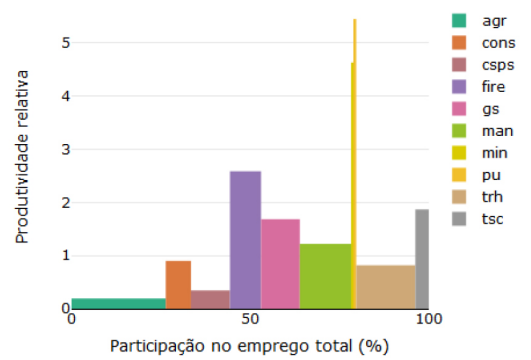

Brasil: 1970

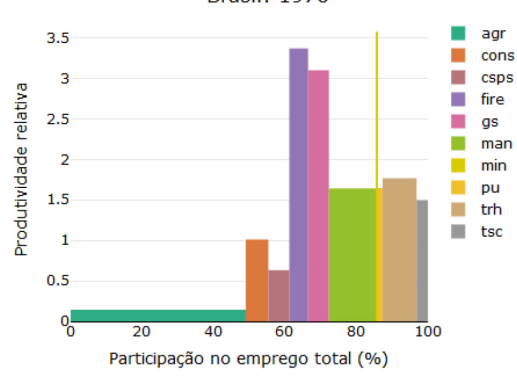

Brasil: 2010

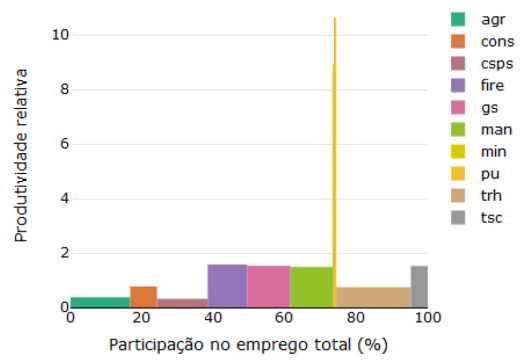

Gráfico 3 - Gaps de produtividade e participação no emprego total, por atividades, diversos anos

Fonte: elaboração própria. Nota: valores da ordenada diferem em cada gráfico.

O movimento do emprego de uma dada atividade para outras com níveis maiores ou menores de produtividade pode ser melhor captado através do Gráfico 4. Nela exibe-se - por décadas ${ }^{16}$ e por três grandes períodos (1950-2010 e em dois subperíodos, 1950-1980 e 1980-2010) - a relação entre a produtividade de cada atividade relativa à produtividade agregada no ano final e a variação na participação setorial do emprego. Os círculos em cada atividade representam a participação no emprego total no ano inicial. Uma mudança estrutural virtuosa (growth-enhancing structural change), isto é, a transferência de trabalhadores de atividades menos produtivas para outras com níveis mais elevados de produtividade que resulta em um crescimento da produtividade agregada, seria indicada por uma correlação positiva entre as variáveis do gráfico. Por outro lado, uma mudança estrutural perversa (growth-reducing structural change), aquela redutora da produtividade agregada, seria indicada por uma correlação negativa.

${ }^{16}$ Em realidade, utiliza-se nesse trabalho o termo "década" para o período entre o primeiro ano de uma década e o primeiro ano da década posterior. Por exemplo, a década de 1950 contempla o período 1950-1960, e não o período 1950-1959. 


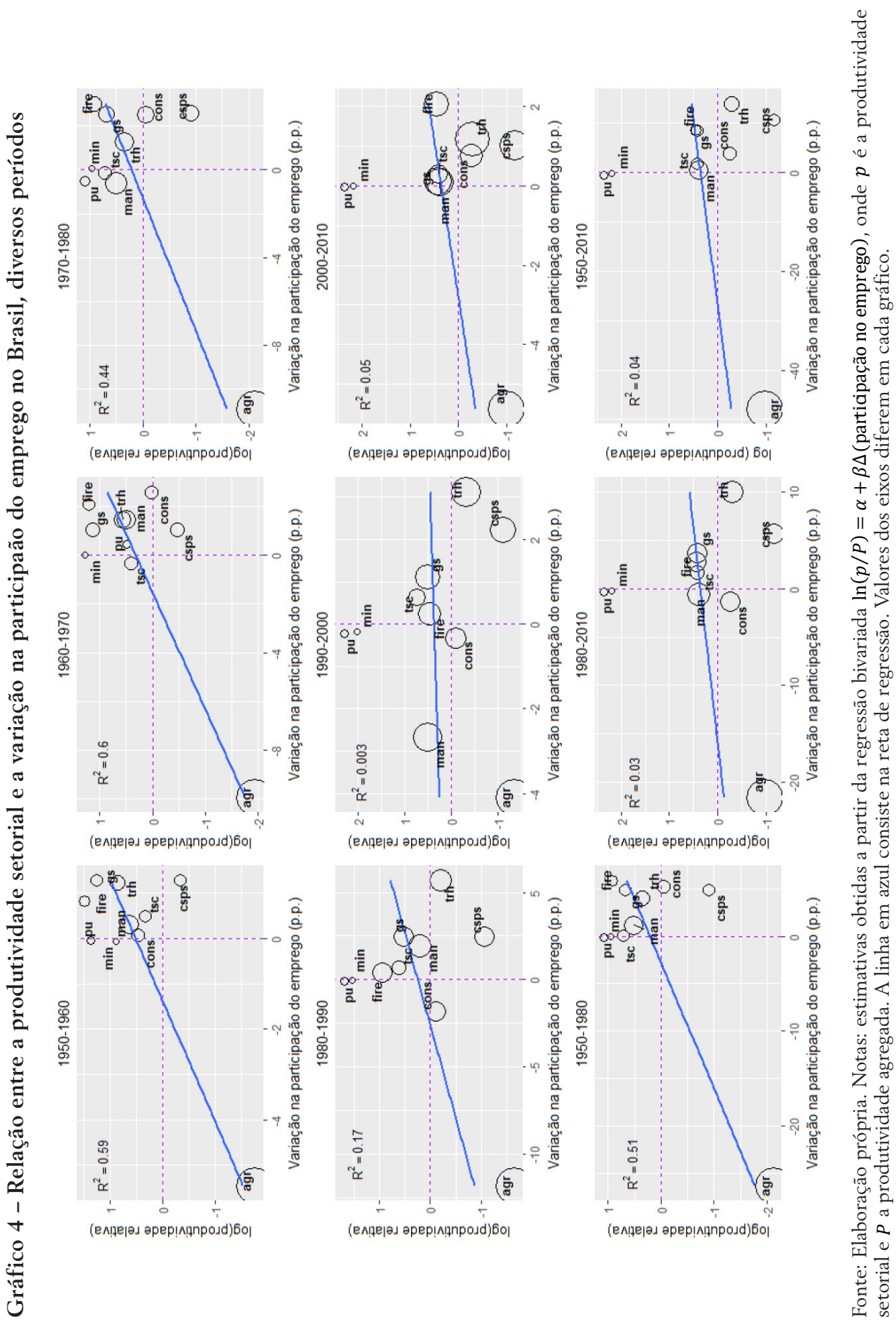


O caminho tradicional da mudança estrutural apresentaria a agropecuária no quadrante inferior-esquerdo (baixa produtividade e encolhimento do tamanho da atividade) e as atividades mais dinâmicas no quadrante superior-direito (maior produtividade e expansão dos seus tamanhos). Foi exatamente isso que ocorreu no Brasil, em maior medida, de 1950 até 1980, quando a agropecuária registrou uma ampla perda de participação no emprego total, que foi absorvido em praticamente todas as atividades, as quais exibiam níveis de produtividade maiores do que a produtividade agregada (exceção feita aos serviços pessoais, csps).

Em consequência, verificou-se uma correlação entre a produtividade setorial e a variação na participação no emprego bastante forte e positiva. Já a partir de 1980, e com mais intensidade em 1990, o papel da mudança estrutural, apesar de não ser redutora de crescimento da produtividade agregada, deixa de ser intenso (correlação praticamente nula). O deslocamento de emprego da agropecuária continuou ocorrendo, mas agora as atividades que mais absorveram a mão de obra foram aquelas com níveis baixos de produtividade (quadrante inferior-direito), sobretudo os serviços pessoais (csps) e os serviços comerciais (trh), justamente aquelas atividades ditas tradicionais do setor de serviços com baixa capacidade de dinamizar o crescimento do produto e da produtividade agregada. Ademais, todas as atividades do setor industrial (mineração, manufatura, construção e utilidades públicas) viram seu tamanho encolher, especialmente a manufatura entre 1990 e 2000.

Embora a saída de emprego da agropecuária tenha levado a uma melhoria na produtividade agregada, o seu impacto teria sido muito mais forte se a mão de obra tivesse migrado para setores mais produtivos e dinâmicos, indicando que o papel da mudança estrutural foi limitado no período 1980-2010. Assim, enquanto que no período 1950-1980 o processo de mudança estrutural foi positivo e virtuoso, no período 1980-2010, apesar de não ter sido redutor de produtividade (a correlação não foi negativa), ele foi perverso. Nesse particular, uma constatação interessante decorre de a mudança estrutural ser positiva praticamente apenas quando se incorpora a agropecuária na análise, mesmo no período de crescimento sustentado (1950-1980). Caso o setor fosse removido da regressão, a reta ajustada se tornaria negativa em quase todos os períodos, indicando que entre os demais setores a mudança estrutural verificada teria efeitos negativos sobre o crescimento econômico (migração do trabalho direcionada para atividades menos produtivas e de baixa qualificação da mão de obra). Assim, a magni- 
tude do efeito positivo da liberação de trabalhadores da agropecuária para a mudança estrutural foi tão grande, sobretudo até 1980, que escondeu um processo perverso de transformação estrutural, estando a mudança estrutural "positiva" praticamente condicionada à realocação de mão de obra dessa atividade em quase todos os períodos analisados.

\section{Resultados da decomposição do crescimento da renda per capita}

Apresentam-se nesta seção os resultados da decomposição de Shapley da renda per capita em mudanças na produtividade do trabalho, na taxa de emprego e no componente demográfico tanto no nível agregado (subseção 5.1) quanto no nível setorial (subseção 5.2).

\subsection{Decomposição no nível agregado}

Conforme pode ser apreendido pela Tabela 3, o desempenho econômico do Brasil de 1950 a 1980 foi bastante robusto e acelerado, alcançando um crescimento de 4,95\% ao ano e chegando a registrar no subperíodo 1970-80 uma taxa anual de 6,73\%. Tal desempenho bastante positivo se deu, basicamente, em função dos ganhos de produtividade do trabalho do período, os quais explicaram $90 \%$ do crescimento da renda per capita entre 1950 e 1980. No referido período, a taxa de emprego e o componente demográfico também contribuíram positivamente para o crescimento da renda per capita, embora em proporções bastante inferiores.

Tabela 3 - Decomposição do crescimento da renda per capita, diversos períodos

\begin{tabular}{ccccc}
\hline \multirow{2}{*}{ Período } & $\begin{array}{c}\text { Renda per capita } \\
\text { (cresc. anualizado \%) }\end{array}$ & Produtividade & Taxa de emprego & Demografia \\
\cline { 3 - 5 } & 4,10 & 4,17 & 0,27 & $-0,33$ \\
$1950-1960$ & 4,05 & 4,29 & $-0,37$ & 0,12 \\
$1960-1970$ & 6,73 & 5,08 & 0,99 & 0,66 \\
$1970-1980$ & $-0,64$ & $-2,08$ & 1,00 & 0,44 \\
$1980-1990$ & $-0,09$ & 0,48 & $-1,26$ & 0,69 \\
$1990-2000$ & 2,16 & 0,89 & 0,73 & 0,54 \\
$2000-2010$ & 4,95 & 4,46 & 0,33 & 0,17 \\
\hline $1950-1980$ & 0,47 & $-0,24$ & 0,15 & 0,56 \\
$1980-2010$ & 2,69 & 2,05 & 0,25 & 0,39 \\
\hline $1950-2010$ & & & & \\
\hline
\end{tabular}

Fonte: Elaboração própria. Nota: A soma das linhas (contribuições em pontos percentuais) é igual à taxa de crescimento da renda per capita ( $2^{\mathrm{a}}$ coluna). 
Por outro lado, no período mais recente (1980-2010), o crescimento da renda per capita se desacelerou com intensidade $(0,47 \%$ ao ano), chegando a ser negativo nos subperíodos 1980-90 e 1990-2000. Diferentemente do período anterior (1950-80), a produtividade do trabalho contribuiu negativamente para o crescimento da renda per capita (além de sua importância ter decrescido com o tempo), enquanto o seu principal determinante foi o componente demográfico e, em menor grau, a taxa de emprego. Entretanto, essas importâncias se alteram nos subperíodos entre 1980-2010.

Em suma, é notória a relevância da produtividade para o desempenho econômico brasileiro de forma positiva na fase de crescimento e de forma negativa na fase de desaceleração, indicando que o seu comportamento apresenta um caráter pró-cíclico. O Brasil colheu os frutos do bônus demográfico desde os anos 1960 e a taxa de emprego contribuiu positivamente em todos os subperíodos, com exceção de 1990-2000, no qual foi o determinante fundamental para o decréscimo da renda per capita. Os resultados obtidos vão na mesma direção aos encontrados por Bonelli (2005) e Torezani (2018) usando dados do Sistema de Contas Nacionais e dos Censos Demográficos na decomposição do PIB e do PIB per capita brasileiros desde 1940, respectivamente, também nas contribuições da produtividade e de variáveis do mercado de trabalho e demográficas . ${ }^{17}$

A partir da relevância da produtividade na explicação do crescimento econômico brasileiro, o Gráfico 5 desagrega os seus resultados nos componentes intrassetorial (within) e mudança estrutural, tanto a estática quanto a dinâmica, além de apresentar os demais componentes da decomposição do crescimento da renda per capita. Como pode ser observado, até 1980, todos os componentes da produtividade registraram contribuições positivas para o crescimento acelerado da renda per capita. O principal responsável pelo crescimento econômico nesse período foi o componente intrassetorial da produtividade, seguido pela realocação de trabalhadores de setores menos produtivos para outros com níveis de produtividade mais elevados (mudança estrutural estática). A contribuição positiva da mudança estru-

${ }^{17}$ Bonelli (2005) decompõe o crescimento do PIB brasileiro entre 1940 e 2000 através de uma decomposição logarítmica das contribuições da produtividade do trabalho (PIB/PO), da taxa de ocupação (PO/PEA), da razão PEA/POP e da própria população (POP). Por sua vez, Torezani (2018) amplia o exercício de Bonelli (2005) para o ano de 2010 (além de atualizar os dados do PIB na referência 2010 do SCN) e inclui dados da população em idade ativa na decomposição. Dessa forma, além da produtividade do trabalho e da taxa de ocupação, também contabiliza as contribuições da taxa de atividade (PEA/PIA) e da taxa de participação (PIA/POP) para o crescimento do PIB per capita do Brasil. 
tural dinâmica indica que os trabalhadores migraram na direção a setores mais dinâmicos, ou seja, aqueles com maiores taxas de crescimento da produtividade.

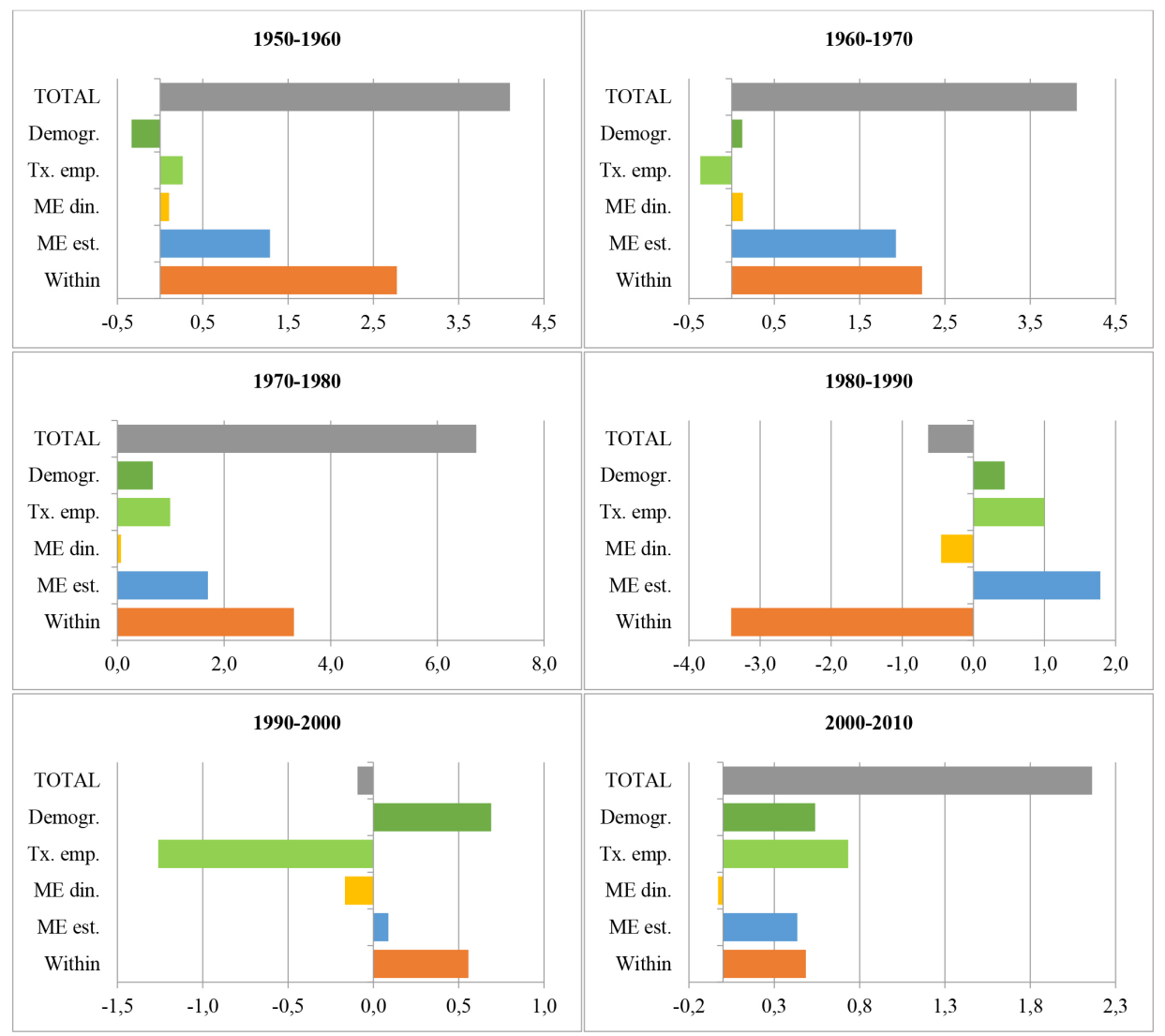

Gráfico 5 - Decomposição do crescimento da renda per capita, diversos períodos

Fonte: elaboração própria. Notas: escalas diferentes em cada gráfico. Desagregação do componente intrassetorial da produtividade (within) em razão capital-trabalho e mudança tecnológica (TFP), respectivamente: $1950-1960$ (-4,05\% e 6,83\%), 1960-1970 (5,14\% e -2,91\%), 1970-1980 (8,58\% e -5,27\%), $1980-1990$ (-7,08\% e 3,68\%), 1990-2000 (1,04\% e -0,48\%), $2000-2010$ (-2,38\% e $2,87 \%)$.

Entretanto, a partir de 1980, há uma alteração na direção da mudança estrutural dinâmica (embora a estática continue contribuindo positivamente em todos subperíodos). Isso indica que os trabalhadores saíram de setores menos produtivos (notadamente a agropecuária) para outros com níveis maiores de produtividade, mas não tão dinâmicos, ou seja, setores 
com pouca capacidade de dinamizarem o crescimento econômico (setores tradicionais da economia, sobretudo os de serviços). Com exceção do subperíodo 1980-1990, nenhum componente da produtividade foi o mais relevante para explicar o crescimento econômico do país como foi em qualquer subperíodo anterior a 1980.

Já o Gráfico 6 expõe de maneira resumida as contribuições de cada um dos componentes para o crescimento da renda per capita em diversos períodos do tempo, subdividindo o componente intrassetorial nas contribuições da relação capital-trabalho e de mudanças tecnológicas. No que tange ao componente intrassetorial, o seu forte crescimento no período 1950-80 se deu pelo crescimento da relação capital-trabalho (sobretudo nas décadas de 1970 e 1980), período no qual foi o responsável pela maior contribuição para o crescimento da renda per capita. Por sua vez, ele foi o componente que mais contribuiu negativamente para o crescimento da renda per capita no período 1980-2010, ao passo que o crescimento da produtividade total dos fatores (mudanças tecnológicas) apresentou contribuição positiva (enquanto havia se mantido estável no período pré-1980).

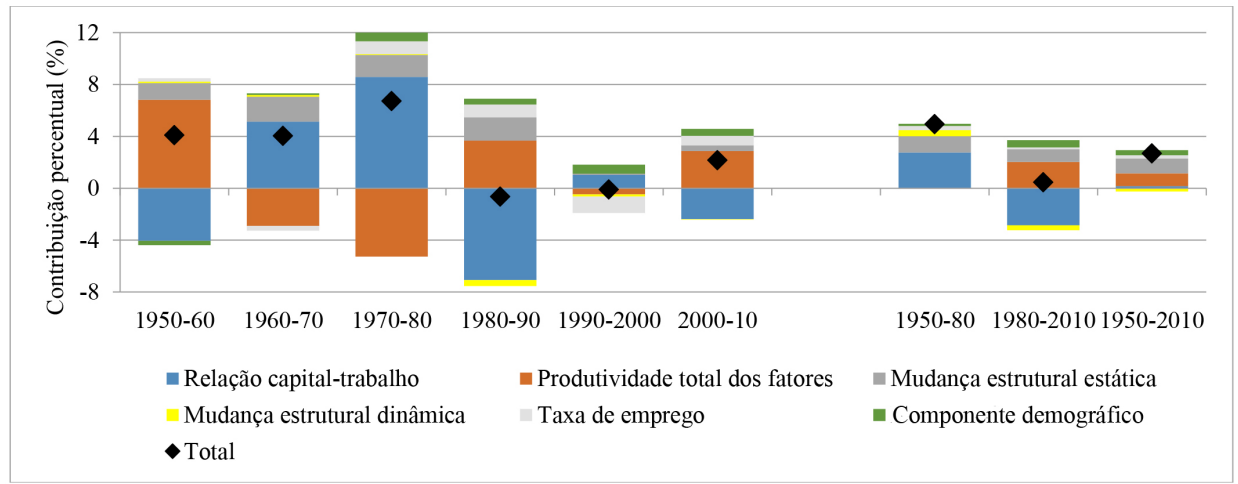

Gráfico 6 - Contribuições percentuais dos componentes da decomposição do crescimento da renda per capita brasileira, diversos períodos

Fonte: elaboração própria.

Os resultados encontrados quanto à contribuição do componente mudança estrutural para o crescimento da renda per capita do Brasil, assim como os de Aldrighi e Colistete (2013) para o crescimento da produtividade brasileira, contrastam com os de Pagés et al. (2010), McMillan e Rodrik 
(2011) para uma amostra de países latino-americanos na análise do período 1990-2005 e com os de Firpo e Pieri (2016) para o crescimento da produtividade do Brasil. Enquanto em Pagés et al. (2010) e Firpo e Pieri (2016) o componente mudança estrutural foi negativo no referido período, o calculado por McMillan e Rodrik (2011) também foi negativo (ou ligeiramente positivo quando calculado com médias ponderadas). Entretanto, a contribuição positiva da mudança estrutural (estática) encontrado aqui (mesmo que até 2010) e por Aldrighi e Colistete (2013) também para 1990-2005 não foi desprezível.

\subsection{Decomposição no nível setorial}

A decomposição setorial revela que o crescimento anual de 4,95\% da renda per capita da economia brasileira no período 1950-80 (primeira tabela da Tabela 4$)^{18}$ foi impulsionado pelas atividades de serviços empresariais e da indústria de transformação, com contribuições de $23 \%$ e $22 \%$, respectivamente, ou seja, essas duas atividades explicaram quase metade do crescimento per capita da economia. Apesar das maiores contribuições das referidas atividades, todas as demais registraram contribuições positivas. A agropecuária foi a única atividade a registrar contração da sua taxa de emprego, indicando que a mão de obra no período se deslocou da agropecuária para as demais atividades, as quais viram a sua participação no emprego total se elevar, em especial as atividades ligadas ao setor de serviços e a construção. Na medida em que a agropecuária tem um nível de produtividade menor do que a da produtividade agregada da economia, a redução na sua participação do emprego, mesmo tendo sido bastante intensa, levou a um maior crescimento da renda per capita. Dessa forma, a sua contribuição foi positiva para a mudança estrutural (assim como para o efeito setorial), pois liberou força de trabalho para atividades com níveis mais elevados de produtividade e taxas de crescimento mais dinâmicas.

Os maiores ganhos estáticos (deslocamento da mão de obra de uma atividade para outras com níveis mais elevados de produtividade) foram registrados pelos serviços empresariais (contribuição de 34\% para a mudança estrutural estática) e pelos serviços governamentais (contribuição de 24\%). Já os ganhos dinâmicos de produtividade foram praticamente insignificantes. ${ }_{18}$ As decomposições setoriais do crescimento da renda per capita brasileira nos períodos 1950-60,
$1960-70$ e 1970-80 encontram-se no Apêndice. 
No que tange ao efeito setorial, todas as atividades exibiram contribuições positivas, com destaque para a indústria de transformação, responsável por um terço do crescimento do ganho setorial total.

Após um crescimento sustentado da renda per capita de 1950 até meados dos anos 1980, o início da década de 1980 trouxe desafios à economia brasileira, a qual não foi capaz de sustentar esse crescimento acelerado, passando por diversas fases turbulentas. No período 1980-2010, o país cresceu a uma taxa média anual de $0,47 \%$. O componente demográfico foi o principal responsável pelo crescimento per capita positivo, compensando a redução de $0,24 \%$ ao ano do crescimento da produtividade, enquanto a taxa de emprego cresceu a uma taxa média anual de 0,15\%.

Tabela 4 - Decomposição setorial do crescimento da renda per capita brasileira, 1950$1980,1980-2010$ e $1950-2010$

\begin{tabular}{|c|c|c|c|c|c|c|c|c|c|}
\hline \multirow{4}{*}{$1950-1980$} & \multicolumn{8}{|c|}{ Contribuição em pontos percentuais } & \multirow{4}{*}{$\begin{array}{c}\text { TOTAL } \\
(\%)\end{array}$} \\
\hline & \multicolumn{7}{|c|}{ PRODUTIVIDADE } & \multirow{3}{*}{$\begin{array}{c}\text { TAXA } \\
\text { DE EM- } \\
\text { PREGO }\end{array}$} & \\
\hline & \multicolumn{3}{|c|}{ Setorial } & \multicolumn{3}{|c|}{ Mudança estrutural } & \multirow{2}{*}{ TOTAL } & & \\
\hline & $K / L$ & TFP & Total & Estática & Dinâmica & Total & & & \\
\hline & 1 & 2 & $3=1+2$ & 4 & 5 & $6=4+5$ & $7=3+6$ & 8 & $9=7+8$ \\
\hline Agropecuária & - & - & 0,20 & 0,34 & 0,53 & 0,87 & 1,07 & $-0,85$ & 0,23 \\
\hline Mineração & - & - & 0,07 & 0,00 & 0,00 & 0,00 & 0,07 & 0,00 & 0,07 \\
\hline Manufatura & - & - & 0,91 & 0,01 & 0,02 & 0,03 & 0,94 & 0,09 & 1,03 \\
\hline Utilidades públicas & - & - & 0,09 & $-0,01$ & 0,00 & $-0,01$ & 0,08 & 0,00 & 0,08 \\
\hline Construção & - & - & 0,19 & 0,05 & $-0,04$ & 0,02 & 0,21 & 0,22 & 0,43 \\
\hline Serv. comerciais & - & - & 0,31 & 0,14 & $-0,02$ & 0,12 & 0,43 & 0,18 & 0,61 \\
\hline Serv. de transporte & - & - & 0,31 & 0,00 & 0,00 & 0,00 & 0,31 & 0,01 & 0,32 \\
\hline Serv. empresariais & - & - & 0,35 & 0,42 & 0,06 & 0,48 & 0,83 & 0,25 & 1,08 \\
\hline Serv. governamentais & - & - & 0,26 & 0,30 & 0,00 & 0,30 & 0,55 & 0,21 & 0,76 \\
\hline Serv. pessoais & - & - & 0,05 & 0,00 & $-0,09$ & $-0,09$ & $-0,04$ & 0,21 & 0,17 \\
\hline Subtotal & 2,76 & $-0,02$ & 2,74 & 1,25 & 0,47 & 1,71 & 4,46 & 0,33 & 4,78 \\
\hline \multicolumn{9}{|c|}{ COMPONENTE DEMOGRÁFICO (10) } & 0,17 \\
\hline \multicolumn{9}{|c|}{ CRESCIMENTO ANUALIZADO DA RENDA PER CAPITA } & 4,95 \\
\hline
\end{tabular}

Fonte: Elaboração própria. Nota: a taxa de crescimento da renda per capita resulta da soma de 9 e 10. 


\begin{tabular}{|c|c|c|c|c|c|c|c|c|c|}
\hline \multirow{4}{*}{$1980-2010$} & \multicolumn{8}{|c|}{ Contribuição em pontos percentuais } & \multirow{4}{*}{$\begin{array}{l}\text { TOTAL } \\
\text { (\%) }\end{array}$} \\
\hline & \multicolumn{7}{|c|}{ PRODUTIVIDADE } & \multirow{3}{*}{$\begin{array}{c}\text { TAXA } \\
\text { DE EM- } \\
\text { PREGO }\end{array}$} & \\
\hline & \multicolumn{3}{|c|}{ Setorial } & \multicolumn{3}{|c|}{ Mudança estrutural } & \multirow{2}{*}{ TOTAL } & & \\
\hline & $\mathrm{K} / \mathrm{L}$ & TFP & Total & Estática & Dinâmica & Total & & & \\
\hline & 1 & 2 & $3=1+2$ & 4 & 5 & $6=4+5$ & $7=3+6$ & 8 & $9=7+8$ \\
\hline Agropecuária & - & - & 0,21 & 0,66 & $-0,11$ & 0,55 & 0,76 & $-0,68$ & 0,08 \\
\hline Mineração & - & - & 0,08 & $-0,01$ & $-0,02$ & $-0,03$ & 0,05 & $-0,01$ & 0,04 \\
\hline Manufatura & - & - & $-0,12$ & $-0,01$ & 0,00 & $-0,01$ & $-0,13$ & 0,00 & $-0,13$ \\
\hline Utilidades públicas & - & - & 0,14 & $-0,02$ & $-0,04$ & $-0,07$ & 0,07 & $-0,01$ & 0,06 \\
\hline Construção & - & - & $-0,06$ & 0,00 & 0,00 & 0,01 & $-0,06$ & $-0,03$ & $-0,09$ \\
\hline Serv. comerciais & - & - & $-0,39$ & 0,14 & $-0,11$ & 0,03 & $-0,37$ & 0,36 & 0,00 \\
\hline Serv. de transporte & - & - & $-0,09$ & 0,06 & $-0,02$ & 0,04 & $-0,04$ & 0,06 & 0,02 \\
\hline Serv. empresariais & - & - & $-0,35$ & 0,14 & $-0,05$ & 0,10 & $-0,25$ & 0,11 & $-0,14$ \\
\hline $\begin{array}{l}\text { Serv. governamen- } \\
\text { tais }\end{array}$ & - & - & $-0,20$ & 0,13 & $-0,03$ & 0,10 & $-0,11$ & 0,14 & 0,03 \\
\hline Serv. pessoais & - & - & $-0,04$ & $-0,12$ & 0,00 & $-0,12$ & $-0,17$ & 0,21 & 0,04 \\
\hline Subtotal & $-2,86$ & 2,03 & $-0,83$ & 0,96 & $-0,38$ & 0,59 & $-0,24$ & 0,15 & $-0,09$ \\
\hline \multicolumn{9}{|c|}{ COMPONENTE DEMOGRÁFICO (10) } & 0,56 \\
\hline \multicolumn{9}{|c|}{ CRESCIMENTO ANUALIZADO DA RENDA PER CAPITA } & 0,47 \\
\hline
\end{tabular}

Fonte: elaboração própria. Nota: a taxa de crescimento da renda per capita resulta da soma de 9 e 10.

\begin{tabular}{|c|c|c|c|c|c|c|c|c|c|}
\hline \multirow{4}{*}{$1950-2010$} & \multicolumn{8}{|c|}{ Contribuição em pontos percentuais } & \multirow{4}{*}{$\begin{array}{c}\text { TOTAL } \\
(\%)\end{array}$} \\
\hline & \multicolumn{7}{|c|}{ PRODUTIVIDADE } & \multirow{3}{*}{$\begin{array}{c}\text { TAXA } \\
\text { DE EM- } \\
\text { PREGO }\end{array}$} & \\
\hline & \multicolumn{3}{|c|}{ Setorial } & \multicolumn{3}{|c|}{ Mudança estrutural } & \multirow{2}{*}{ TOTAL } & & \\
\hline & $K / L$ & TFP & Total & Estática & Dinâmica & Total & & & \\
\hline & 1 & 2 & $3=1+2$ & 4 & 5 & $6=4+5$ & $7=3+6$ & 8 & $9=7+8$ \\
\hline Agropecuária & - & - & 0,36 & 0,31 & 0,28 & 0,59 & 0,95 & $-0,80$ & 0,15 \\
\hline Mineração & - & - & 0,10 & 0,00 & $-0,02$ & $-0,02$ & 0,08 & 0,00 & 0,07 \\
\hline Manufatura & - & - & 0,35 & 0,00 & 0,00 & 0,01 & 0,35 & 0,04 & 0,39 \\
\hline Utilidades públicas & - & - & 0,17 & $-0,01$ & $-0,06$ & $-0,07$ & 0,10 & $-0,01$ & 0,09 \\
\hline Construção & - & - & 0,05 & 0,02 & $-0,02$ & 0,00 & 0,05 & 0,09 & 0,13 \\
\hline Serv. comerciais & - & - & $-0,06$ & 0,24 & $-0,17$ & 0,07 & 0,01 & 0,30 & 0,31 \\
\hline Serv. de transporte & - & - & 0,12 & 0,01 & 0,01 & 0,02 & 0,14 & 0,04 & 0,18 \\
\hline Serv. empresariais & - & - & 0,01 & 0,31 & $-0,08$ & 0,23 & 0,24 & 0,18 & 0,42 \\
\hline $\begin{array}{l}\text { Serv. governamen- } \\
\text { tais }\end{array}$ & - & - & 0,04 & 0,27 & $-0,07$ & 0,20 & 0,24 & 0,18 & 0,42 \\
\hline Serv. pessoais & - & - & 0,01 & 0,00 & $-0,10$ & $-0,11$ & $-0,10$ & 0,22 & 0,13 \\
\hline Subtotal & 0,17 & 0,98 & 1,15 & 1,15 & $-0,25$ & 0,90 & 2,05 & 0,25 & 2,30 \\
\hline \multicolumn{9}{|c|}{ COMPONENTE DEMOGRÁFICO (10) } & 0,39 \\
\hline \multicolumn{9}{|c|}{ CRESCIMENTO ANUALIZADO DA RENDA PER CAPITA } & 2,69 \\
\hline
\end{tabular}

Fonte: Elaboração própria. Nota: a taxa de crescimento da renda per capita resulta da soma de 9 e 10. 
A partir da decomposição setorial do período 1980-2010 (segundo período da Tabela 4) ${ }^{19}$ é possível verificar que a soma das contribuições setoriais para o crescimento da renda per capita foi menor do que a contribuição do componente demográfico, em oposição ao que se verificou no subperíodo anterior. A atividade que mais contribuiu para o crescimento da renda per capita foi a agropecuária (17\%), mesmo vendo reduzir seu tamanho na estrutura de empregos, sendo, então, compensada pelo crescimento da sua produtividade, sobretudo pela sua contribuição positiva para o crescimento da produtividade agregada, da mesma forma como no subperíodo anterior. Em termos de emprego, todas as atividades industriais viram diminuir o seu tamanho. Em contrapartida, todas as atividades pertencentes ao setor de serviços aumentaram a sua participação no emprego total. Entretanto, as atividades tradicionais foram as que mais receberam mão de obra da agropecuária. No que tange à produtividade dos setores, verificou-se crescimento apenas na agropecuária, utilidades públicas e mineração, crescimento esse resultante do efeito setorial. O papel da mudança estrutural no processo de crescimento da renda per capita foi inexpressivo, exibindo, em geral, ganhos estáticos e perdas dinâmicas.

Desconsiderando os subperíodos anteriores e investigando os determinantes do crescimento da renda per capita da economia brasileira no período 1950-2010 (2,69\% a.a.) a partir da decomposição setorial (terceira tabela da Tabela 4), observa-se que as maiores contribuições foram registradas pelos serviços empresariais (16\%) e pelos serviços governamentais (16\%), pela indústria de transformação (14\%) e pelos serviços comerciais (12\%). Entretanto, diferenças importantes surgem quando se analisa os componentes que mais explicaram a dinâmica dessas atividades. Enquanto a contribuição das duas primeiras atividades se deu em função dos ganhos estáticos de produtividade, a contribuição da manufatura se concentrou nos ganhos setoriais de produtividade e os serviços comerciais no crescimento da taxa de emprego.

Por fim, o Gráfico 7 expõe, de forma resumida, as contribuições de cada atividade econômica e do componente demográfico para o crescimento da renda per capita do Brasil em diversos períodos. Diferentemente dos dados anteriores, agrupa-se as atividades do setor de serviços em duas classificações, quais sejam, serviços tradicionais e serviços modernos ${ }^{20}$

${ }^{19}$ As decomposições setoriais do crescimento da renda per capita brasileira nos períodos 1980-90, 1990-2000 e 2000-10 encontram-se no Apêndice.

20 A distinção entre os dois resume-se ao potencial das atividades de dinamizar o crescimento econômico agregado. Os serviços tradicionais (aqueles não-tradables, com menores níveis de produtividade 
além de agrupar as atividades industriais com exceção da indústria de transformação. ${ }^{21}$ Verifica-se que o desempenho da manufatura, dos serviços tradicionais e dos serviços modernos foram importantes para explicar o crescimento da renda per capita de 1950 a 1980, período no qual a economia brasileira registrou um crescimento per capita acelerado. Já as taxas negativas de 1980 a 2000 só não foram maiores por conta do componente demográfico do país, que contrabalanceou o referido desempenho negativo. Já o crescimento do período 2000-10 foi resultante, sobretudo, do desempenho positivo dos serviços tradicionais e do componente demográfico.

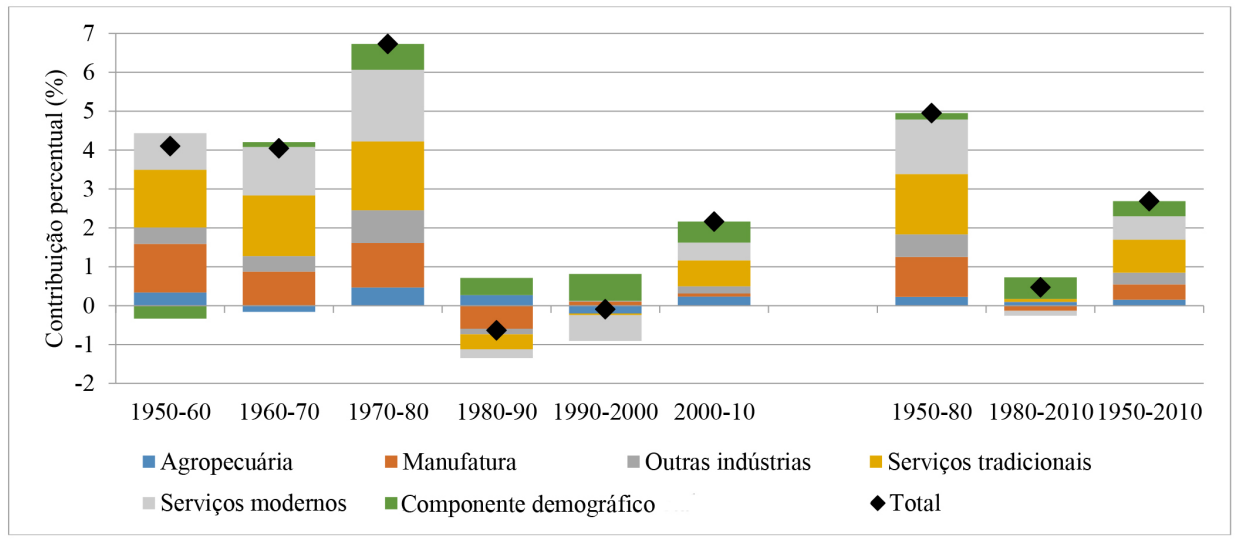

Gráfico 7 - Contribuições percentuais das atividades econômicas e do componente demográfico para o crescimento da renda per capita brasileira, diversos períodos

Fonte: Elaboração própria.

Os resultados das elevadas contribuições da produtividade setorial da agropecuária para o crescimento da renda per capita brasileira ao longo de todo o período analisado estão em consonância com os ganhos de produtividade da atividade verificados por Gasques et al. (2016) no período 1975-2014. Os autores apontam alguns fatores na explicação desse resultado decorrentes das grandes mudanças da agropecuária brasileira nas décadas mais recentes e o seu processo de modernização. Entre eles se destacam as

e de baixa qualidade das ocupações e com menor capacidade de transbordamento para outras atividades) agrupam os serviços comerciais, governamentais e pessoais, enquanto os serviços modernos agrupam os serviços de transporte e empresariais.

${ }^{21}$ Da mesma forma que os serviços modernos, a dinâmica da manufatura é vista como um grande determinante para o crescimento econômico (Kaldor, 1966; Szirmai, 2013; Szirmai e Verspagen, 2015). 
alterações nas políticas agrícolas, a elevação no consumo de fertilizantes, o crescimento da demanda mundial por produtos agropecuários e a maior inserção do Brasil no mercado internacional, o deslocamento espacial das atividades que vem permitindo maior área de cultivo, o crescimento do mercado interno, os investimentos em pesquisa e a descoberta de novas tecnologias, e o uso mais intensivo de máquinas agrícolas.

Outro fator explicativo também pode ser apontado, qual seja, a redução em termos absolutos e relativos do pessoal ocupado (downsizing), que faz diminuir o denominador da medida de produtividade, que, por sua vez, faz crescer a produtividade da atividade. Adicionalmente, as elevadas contribuições setoriais da agropecuária também podem ser entendidas a partir do fato estilizado sobre o processo de desenvolvimento econômico encontrado por McMillan e Rodrik (2011) entre a diferença de produtividade entre a atividade agropecuária e as não-agropecuárias. Os autores indicam uma relação no formato de $U$ ao longo do tempo, onde primeiramente essa diferença diminui com o passar do tempo e, posteriormente, se eleva. De fato, o Brasil estaria na parte ascendente da curva, pois a relação da produtividade agropecuária e a não-agropecuária era de 0,085 em 1950, passou para 0,078 em 1980 e para 0,329 em 2010.

A reduzida contribuição da indústria extrativa para o crescimento da renda per capita ao longo de todo o período encontra explicação na possibilidade limitada de uma economia com vantagens comparativas em recursos naturais contribuir estruturalmente para o crescimento em virtude de não gerarem ou absorverem muitos empregos (McMillan e Rodrik, 2011).

Os resultados obtidos sobre as maiores contribuições positivas da manufatura e dos serviços tradables para o crescimento da renda per capita brasileira no período 1950-1980 (aquele de maior crescimento econômico) vão de encontro aos resultados encontrados por Timmer e de Vries (2009) e Nassif et al. (2020) dessas mesmas atividades para o crescimento da produtividade. Ao mesmo tempo, os resultados encontrados para o período 1980-2010 também estão alinhados aos dos autores na averiguação de contribuições negativas de ambas as atividades no período 1980-2005 em Timmer e de Vries (2009) e no período 1980-2011 em Nassif et al. (2020).

A baixa contribuição da indústria verificada para o crescimento da renda per capita neste trabalho no período pós-1980 encontra resultados semelhantes para o baixo crescimento da produtividade agregada do Brasil em 
diversos trabalhos (Carvalheiro, 2003; Aldrighi e Colistete, 2013; Squeff e De Negri, 2013; Bonelli, 2014; Jacinto e Ribeiro, 2015; Torezani, 2018). Esses resultados insatisfatórios da indústria pós-1980 trazem algumas implicações para a dinâmica da renda per capita, uma vez que é relativamente difundido na literatura empírica recente o seu papel-chave no processo de crescimento econômico (Rodrik, 2013; Szirmai e Verspagen, 2015; Haraguchi et al., 2017), dado que a indústria pode ser vista como um setor essencial ao crescimento econômico por diversas características inerentes ao próprio setor (Kaldor, 1966; Szirmai, 2013; Szirmai e Verspagen, 2015). O processo precoce de realocação de mão de obra da agropecuária e da indústria para os serviços (tradicionais) verificado ao longo de todo o período analisado (antes de o Brasil atingir um nível elevado de renda per capita) atrelado ao aumento, no mesmo período, da taxa de emprego de atividades de serviços tradicionais, levam à consideração de um processo prematuro de desindustrialização da economia brasileira.

Por fim, o setor de serviços foi o principal responsável na explicação das taxas de crescimento da renda per capita brasileira ao longo do período investigado. O setor absorveu muitos trabalhadores da agropecuária e da indústria e registrou contribuições relevante em termos de produtividade, o que indica um processo de "servitização" da economia. A desagregação dos dados permitiu compreender, de alguma forma, a heterogeneidade existente dentro do setor de serviços, o que se torna relevante na medida em que algumas dessas atividades (aquelas mais modernas) também são capazes de promover e sustentar o crescimento econômico (Dasgupta e Singh, 2007; Jorgenson e Timmer, 2011; Eichengreen e Gupta, 2013). Entretanto, os resultados mostraram que mesmo no período de maior crescimento (1950-80) os serviços tradicionais contribuíram mais do que os serviços modernos e que já absorvia trabalhadores dos demais setores, tal como verificado em Nassif et al. (2020). No período posterior (19802010), os serviços modernos contribuíram negativamente para o crescimento da renda per capita, enquanto os serviços tradicionais continuaram a sua contribuição positiva e ganharam participação e preponderância na economia, o que indica uma dinâmica não favorável ao país. 


\section{Considerações finais}

O presente artigo investigou os determinantes do crescimento da renda per capita da economia brasileira no período 1950-2010 a partir da mensuração da contribuição da produtividade, da taxa de emprego e da demografia, tanto de maneira agregada quanto de maneira setorial pela decomposição de Shapley. A principal contribuição original do artigo decorreu da estratégia empírica utilizada, a qual possibilitou identificar a contribuição da mudança estrutural (e da taxa de emprego) sobre o crescimento da renda per capita em termos setoriais, na medida que a literatura apenas identifica tal contribuição para o crescimento da produtividade agregada, que é apenas um dos fatores que afetam o crescimento econômico. Assim, na abordagem ampliada utilizada no presente trabalho, também se mensurou as contribuições do componente demográfico e da taxa de emprego para o crescimento da renda per capita da economia brasileira, fornecendo uma perspectiva mais completa sobre os determinantes agregados e setoriais do crescimento econômico.

Apesar de os resultados dependerem do subperíodo investigado, pode-se observar o papel relevante da produtividade para os ganhos e perdas de crescimento econômico, bem como o papel da taxa de emprego e do componente demográfico na dinâmica econômica do país. De 1950 até 1980 o Brasil experimentou um período de intenso e sustentado crescimento econômico e transformação estrutural da sua economia, com o deslocamento dos fatores de produção de setores menos produtivos para outros com maiores níveis e taxas de produtividade, contribuindo para um processo virtuoso de convergência tanto interna quanto externa. No período pós1980, todavia, a economia brasileira não foi capaz de manter esse padrão de crescimento.

Os resultados obtidos das decomposições setoriais indicam para além da dicotomia entre indústria e serviços, isto é, o crescimento econômico foi liderado tanto pela indústria (de transformação) quanto pelos serviços, sobretudo pelos serviços modernos, consistente com o debate sobre o papel dessas atividades no processo de desenvolvimento econômico. Entretanto, também se verificou que os serviços tradicionais vêm ganhando participação na economia e absorvendo trabalhadores de outras atividades com níveis maiores de produtividade desde o período de forte crescimento (1950-80). A indústria de transformação, por outro lado, vem perdendo 
dinamismo nas últimas décadas, chegando a contribuir negativamente para o crescimento da renda per capita entre 1980-2010.

Uma constatação pertinente dos resultados obtidos que acarreta em implicações bastante relevantes para o crescimento futuro brasileiro é que, apesar de a economia brasileira ter passado por uma situação de bônus demográfico nas últimas décadas, esse deixou de existir em meados da década de 2010. O componente demográfico aqui calculado, que desde a década de 1960 contribuiu positivamente para o crescimento da renda per capita (facilitava e garantia uma parte desse crescimento), a partir de agora passará a contribuir negativamente, reduzindo a expansão da força de trabalho. Isso implica em uma maior dificuldade de a população ocupada aumentar, pois esta é limitada pela PEA que, por seu turno, é influenciada pela PIA. Além disso, existe um natural limite superior de crescimento para a taxa de emprego, que não pode crescer indefinidamente. Embora a demanda por trabalhadores tenda a crescer nas próximas décadas, já começa a se desenhar restrições de cunho demográfico ao aumento da força de trabalho, incorrendo, no médio prazo, em um descompasso entre a demanda e oferta de trabalhadores. Por todas essas limitações, o crescimento da renda per capita das próximas décadas dependerá fundamentalmente dos ganhos de produtividade.

Alguns limites teórico-metodológicos já mencionados devem ser levados em consideração na avaliação dos resultados obtidos. Primeiramente, os exercícios de decomposição partem de uma identidade contábil onde é possível levar em consideração apenas alguns determinantes do crescimento da renda per capita. Como a metodologia é orientada pelo lado da oferta, importantes mudanças na demanda são tomadas como exógenas. Em segundo lugar, utiliza-se a PIA como numerador da taxa de emprego, e não a PEA, o que tende a subestimar a contribuição desse componente no cálculo da decomposição. Ademais, por se trabalhar como uma série com extensa cobertura temporal (1950-2010), perde-se a possibilidade de se trabalhar com dados setoriais mais desagregados, o que permitiria auferir as contribuições da produtividade setorial e da mudança estrutural com maior propriedade, sobretudo no que se refere à indústria de transformação, a qual apenas dispõe de dados agregados, e do setor de serviços, na medida que existe uma heterogeneidade produtiva bastante acentuada dentro da manufatura e do setor de serviços. 
De qualquer forma, os resultados aqui obtidos de forma original se mostram relevantes para contribuir para o melhor entendimento dos determinantes do crescimento da renda per capita brasileira e, sobretudo, das contribuições setoriais para o referido crescimento. Alguns possíveis caminhos de pesquisa futura consistem na comparação dos resultados do Brasil com outras economias semelhantes para averiguar algum comportamento anômalo, bem como investigar os principais fatores, sejam macroeconômicos, microeconômicos ou institucionais, que explicam o comportamento dos componentes intrassetorial e mudança estrutural calculados nas decomposições.

\section{Referências}

Aldrighi, D., e R. P. Colistete. 2013. "Industrial growth and structural change: Brazil in a long-run perspective". Working Paper Series, no. 10.

Araujo, R. A., e G. T. Lima. 2007. "A structural economic dynamic approach to balance-of-payments constrained growth”. Cambridge Journal of Economics 31, no. 5: 755-774.

Araujo, R. A. 2013. "Cumulative causation in a structural economic dynamic approach to economic growth and uneven development”. Structural Change and Economic Dynamics 24: 130-140.

Baumol, W. J. 1967. "Macroeconomics of unbalanced growth: the anatomy of urban crisis". The American Economic Review 57, no. 3: 415-426.

Barro, R. 1991. "Economic growth in a cross section of countries". Quarterly Journal of Economics 106, no. 2: 407-443.

Bonelli, R. 2002. "Labor productivity in Brazil during the 1990s”. Texto para Discussão IPEA, no. 906.

Bonelli, R. 2005. “O que causou o crescimento econômico no Brasil?” In Economia brasileira contemporânea: 1945-2004., organizado por F. Giambiagi, A. Villela, L. B. de Castro, e J. Hermann, 307-334. Rio de Janeiro: Elsevier.

Bonelli, R. 2014. "Produtividade e armadilha do lento crescimento". In Produtividade no Brasil: desempenhos e determinantes, v. 1, organizado por F. De Negri, e L. R. Cavalcante, 111-141. Brasília: ABDI: IPEA.

Carvalheiro, N. 2003. "Uma decomposição do aumento da produtividade do trabalho no Brasil durante os anos 90”. R. Econ. Contemp. 7, no. 1: 81-109.

Caselli, F. 2005. "Accounting for cross-country income differences". In Handbook of economic growth, editado por A. Phillipe, e D. Steven 679 - 741. Amsterdam: North-Holland Press.

Cavalcante, L. R., e F. De Negri. 2014. "Evolução recente dos indicadores de produtividade no Brasil". In Produtividade no Brasil: desempenhos e determinantes, v. 1, organizado por F. De Negri, e L. R. Cavalcante, 143-171. Brasília: ABDI: IPEA.

Chenery, H. 1960. "Patterns of industrial growth". American Economic Review 50, no. 4: 624-653.

Chenery, H. B, S. Robinson, e M. Syrquin., eds. 1986. Industrialization and growth: a comparative study. New York: Oxford University Press.

Chenery, H. B, e M. Syrquin. 1975. Patterns of development. London: Oxford University Press. 
Chenery, H, e L. Taylor. 1968. "Development patterns: Among countries and over time”. Review of Economics and Statistics 50, no. 4: 391-416.

Clark, C. 1940. The conditions of economic progress. London: Macmillan.

Dasgupta, S, e A. Singh. 2007. "Manufacturing, services and premature de-industrialization in developing countries: a Kaldorian analysis". In Advancing development. Studies in development economics and policy, editado por Mavrotas G e A. Shorrocks, 435-454. Palgrave Macmillan, London.

de Vries, G, M. Timmer, e K. de Vries. 2015. "Structural transformation in Africa: static gains, dynamic losses". The Journal of Development Studies 51, no. 6: 674-688.

Duarte, M., e D. Restuccia. 2010. "The role of the structural transformation in aggregate productivity". Quarterly Journal of Economics 125, no. 1: 129-173.

Eberhardt, M, e F. Teal. 2013. "Structural change and cross-country growth empirics". World Bank Economic Review 27, no. 2: 229-271.

Eichengreen, B, e P. Gupta. 2013. "The two waves of service-sector growth". Oxford Economic Papers 65, no. 1: 96-123.

Fabricant, S. 1942. Employment in manufacturing, 1899-1939. New York: NBER.

Firpo, S, e R. Pieri. 2016. "Structural change, productivity growth, and trade policy in Brazil". In Structural change, fundamentals, and growth: a framework and case studies, editado por McMillan, M, D. Rodrik, e C. Sepúlveda., 267-292. Washington, DC: International Food Policy Research Institute.

Fisher, A. G. 1939. "Primary, secondary and tertiary production". Economic Record 15, no. 1: 24-38.

Gasques, J. G, M. R. P. Bacchi, L. Rodrigues, E. T. Bastos, e C. Valdes. 2016. "Produtividade da agricultura brasileira: a hipótese da desaceleração". In Agricultura, transformação produtiva e sustentabilidade. Brasília, DF: IPEA, organizado por Vieira Filho, J. E. R., e J. G Gasques, 143-163.

Gollin, D. 2002. "Getting income shares right". Journal of Political Economy 110, no. 2: 458-474.

Gouvea, R. R, e G. T. Lima. 2013. "Balance-of-payments-constrained growth in a multisectoral framework: a panel data investigation". Journal of Economic Studies 40, no. 2: 240-254.

Haile, F. 2018. "Structural change in Africa: a tale of gain and loss". Policy Research Working Paper 8336. World Bank Group: Macroeconomics, Trade and Investment Global Practice Group. Washington, D.C.: World Bank.

Haddad, C. L. S. 1980. “Crescimento econômico do Brasil, 1900-1976”. In Economia brasileira: uma visão histórica, organizado por Neuhaus, P. Rio de Janeiro: Campus.

Haraguchi, N, C. F. C. Cheng, e E. Smeets. 2017. "The importance of manufacturing in economic development: has this changed?" World Development 93: 293-315.

Herrendorf, B, R. Rogerson, e A. Valentinyi. 2014. "Growth and structural transformation”. In Handbook of economic growth, v. 2., editado por Aghion, P., e S. Durlauf, 855-941. Amsterdam: North-Holland.

Hidalgo, C. A, e R. Hausmann. 2009. "The building blocks of economic complexity". Proceedings of the National Academy of Sciences of the United States of America 106, no. 26: 10570-10575.

Imbs, J. M., e R. Wacziarg. 2003. "Stages of diversification". The American Economic Review 93, no. 1: 63-86.

Jacinto, P. de A, e E. P. Ribeiro. 2015. "Crescimento da produtividade no setor de serviços e da indústria no Brasil: dinâmica e heterogeneidade”. Economia Aplicada 19, no. 3: 401-427.

Jorgenson, D. W e M. P. Timmer. 2011. "Structural change in advanced nations: a new set of stylized facts". The Scandinavian Journal of Economics 113, no. 1: 1-29.

Kaldor, N. 1966. Causes of the slow rate of economic growth of the United Kingdom: an inaugural lecture. Cambridge: Cambridge University Press.

Krüger, J. J. 2008. "Productivity and structural change: a review of the literature". Journal of Economic Surveys 22, no. 2 : 330-363. 
Kuznets, S. 1957. "Quantitative aspects of the economic growth of nations": II. Industrial distribution of national product and labor force. Economic Development and Cultural Change 5, no. 4: 1-111.

Kuznets, S. 1966. Modern economic growth. New Haven, CT: Yale University Press.

Kuznets, S. 1971. Economic growth of nations: total output and production structure. Cambridge, Mass.: Harvard University Press.

Levine, R, e D. Renelt. 1992. “A sensitivity analysis of cross-country growth regressions”. American Economic Review 82, no. 4: 942-963.

Lewis, A. 1954. “Economic development with unlimited supplies of labour”. Manchester School 28, no. 2: 139-191.

Maddison, A. 1980. "Economic growth and structural change in advanced countries". In Western economies in transition: structural change and adjustment policies in industrial countries, editado por Levenson, I, e J. Wheeler. London: Croom Helm.

Mankiw, N. G, D. Romer, e D. N. Weil. 1992. "A contribution to the empirics of economic growth". The Quarterly Journal of Economics 107, no. 2: 407-437.

Martins, P. M. G. 2019. "Structural change: pace, patterns and determinants". Review of Development Economics 23, no. 1: 1-32.

Mcmillan, M, e D. Headey. 2014. "Introduction - understanding structural transformation in Africa". World Development 63: 1-10.

Mcmillan, M, e D. Rodrik. 2011. “Globalization, structural change and productivity growth”. In Making globalization socially sustainable, editado por Bacchetta, M. e M. Jense, 49-84. Geneva: International Labour Organization and World Trade Organization.

Nassif, A., L. Morandi, E. Araújo, e C. Feijó.2020. "Economic development and stagnation in Brazil (19502011)". Structural Change and Economic Dynamics 53, no. 1: 1-15.

Ocampo, J. A., C. Rada, e L. Taylor. 2009. Growth and policy in developing countries: a structuralist approach. New York: Columbia University Press.

Pagés, C. ed. 2010. The age of productivity: transforming economies from the bottom up. Washington, DC: Inter-American Development Bank.

Pasinetti, L. L. 1993. Structural economic dynamics: a theory of the economic consequences of human learning. Cambridge: Cambridge University Press.

Pritchett, L, e L. Summers. 2014. “Asiaphoria meets regression to the mean” NBER Working Paper 20573.

Rodrik, D. 2013. "Unconditional convergence in manufacturing”. The Quarterly Journal of Economics 128, no. 1: 165-204.

Shapley, L. 1953. "A value for n-person games". In Contributions to the theory of games, vol. 2, editado por Kuhn, H. W, e A. W. Tucker. Princeton University Press.

Shorrocks, A. 2013. "Decomposition procedures for distributional analysis: A unified framework based on the Shapley value". Journal of Economic Inequality 11, no. 1: 99-126.

Silva, E. G, e A. A. C. Teixeira. 2008. "Surveying structural change: seminal contributions and a bibliometric account". Structural Change and Economic Dynamics 19, no. 4: 273-300.

Squeff, G. C, e F. De Negri. 2013. "Produtividade do trabalho e rigidez estrutural no Brasil nos anos 2000”. In Radar: tecnologia, produção e comércio exterior, n. 28. Brasília: IPEA.

Szirmai, A. 2013. "Manufacturing and economic development". In Pathways to industrialization in the twenty-first century: new challenges and emerging paradigms, editado por Szirmai, A., W. Naudé, e L. Alcorta, 53-75. Oxford: Oxford University Press

Szirmai, A, B. Verspagen. 2015. "Manufacturing and economic growth in developing countries, 1950-2005". Structural Change and Economic Dynamics 34, no. 1: 46-59.

Temple, J. 2005. "Dual economy models: A primer for growth economists”. Manchester School 73, no. 4: 435-478. 
Temple, J, e L. Wößmann. 2006. "Dualism and cross-country growth regressions”. Journal of Economic Growth 11, no. 3: 187-228.

Timmer, M. P, G. J. de Vries. 2009. "Structural change and growth accelerations in Asia and Latin America: a new sectoral data set". Cliometrica 3, no. 2: 165-190.

Timmer, M. P, e A. Szirmai. 2000. "Productivity growth in Asian manufacturing: the structural bonus hypothesis examined”. Structural Change and Economic Dynamics 11, no. 4: 371-392.

Torezani, T. A. 2018. "Evolução da produtividade brasileira: mudança estrutural e dinâmica tecnológica em uma abordagem multissetorial.". Tese de Doutorado. Programa de Pós-Graduação em Economia, Faculdade de Ciências Econômicas, Universidade Federal do Rio Grande do Sul.

Vollrath, D. 2009. "The dual economy in long-run development". Journal of Economic Growth 14, no. 4: $287-312$.

World Bank. 2012. "Job generation and growth decomposition tool: understanding the sectoral pattern of growth and its employment and productivity". Reference Manual and User's Guide, Version 1.0. 


\section{APÊNDICE}

Tabela A - Decomposição setorial do crescimento da renda per capita brasileira, por décadas

\begin{tabular}{|c|c|c|c|c|c|c|c|c|c|}
\hline \multirow{4}{*}{$1950-1960$} & \multicolumn{8}{|c|}{ Contribuição em pontos percentuais } & \multirow{4}{*}{$\begin{array}{c}\text { TOTAL } \\
\text { (\%) }\end{array}$} \\
\hline & \multirow{2}{*}{\multicolumn{3}{|c|}{ Setorial }} & PRODUTI & IDADE & & \multirow{3}{*}{ TOTAL } & \multirow{3}{*}{$\begin{array}{c}\text { TAXA } \\
\text { DE EM- } \\
\text { PREGO }\end{array}$} & \\
\hline & & & & \multicolumn{3}{|c|}{ Mudança estrutural } & & & \\
\hline & $\mathrm{K} / \mathrm{L}$ & TFP & Total & Estática & Dinâmica & Total & & & \\
\hline & 1 & 2 & $3=1+2$ & 4 & 5 & $6=4+5$ & $7=3+6$ & 8 & $9=7+8$ \\
\hline Agropecuária & - & - & 0,28 & 0,36 & 0,10 & 0,46 & 0,73 & $-0,40$ & 0,34 \\
\hline Mineração & - & - & 0,08 & 0,00 & 0,00 & $-0,01$ & 0,07 & $-0,01$ & 0,07 \\
\hline Manufatura & - & - & 1,16 & 0,02 & 0,01 & 0,03 & 1,19 & 0,07 & 1,25 \\
\hline Utilidades públicas & - & - & 0,12 & $-0,01$ & 0,00 & $-0,02$ & 0,10 & 0,00 & 0,10 \\
\hline Construção & - & - & 0,23 & 0,00 & 0,00 & 0,00 & 0,24 & 0,02 & 0,26 \\
\hline Serv. comerciais & - & - & 0,25 & 0,22 & $-0,01$ & 0,21 & 0,46 & 0,15 & 0,61 \\
\hline Serv. de transporte & - & - & 0,18 & 0,02 & 0,00 & 0,02 & 0,20 & 0,06 & 0,26 \\
\hline Serv. empresariais & - & - & 0,27 & 0,30 & 0,02 & 0,32 & 0,59 & 0,09 & 0,68 \\
\hline $\begin{array}{l}\text { Serv. governamen- } \\
\text { tais }\end{array}$ & - & - & 0,18 & 0,40 & 0,00 & 0,40 & 0,58 & 0,14 & 0,72 \\
\hline Serv. pessoais & - & - & 0,04 & 0,00 & $-0,02$ & $-0,02$ & 0,01 & 0,14 & 0,16 \\
\hline Subtotal & $-4,05$ & 6,83 & 2,78 & 1,29 & 0,10 & 1,39 & 4,17 & 0,27 & 4,43 \\
\hline \multicolumn{9}{|c|}{ COMPONENTE DEMOGRÁFICO (10) } & $-0,33$ \\
\hline \multicolumn{9}{|c|}{ CRESCIMENTO ANUALIZADO DA RENDA PER CAPITA } & 4,10 \\
\hline
\end{tabular}

Fonte: Elaboração própria. Nota: a taxa de crescimento da renda per capita resulta da soma de 9 e 10.

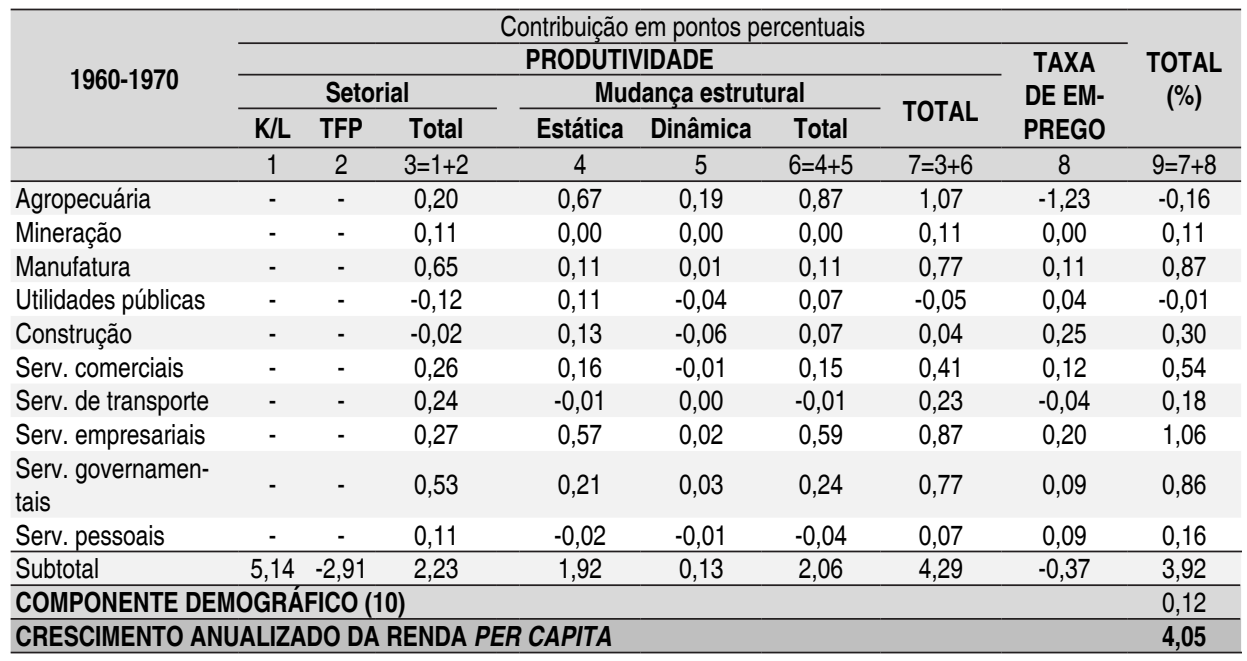

Fonte: Elaboração própria. Nota: a taxa de crescimento da renda per capita resulta da soma de 9 e 10 . 


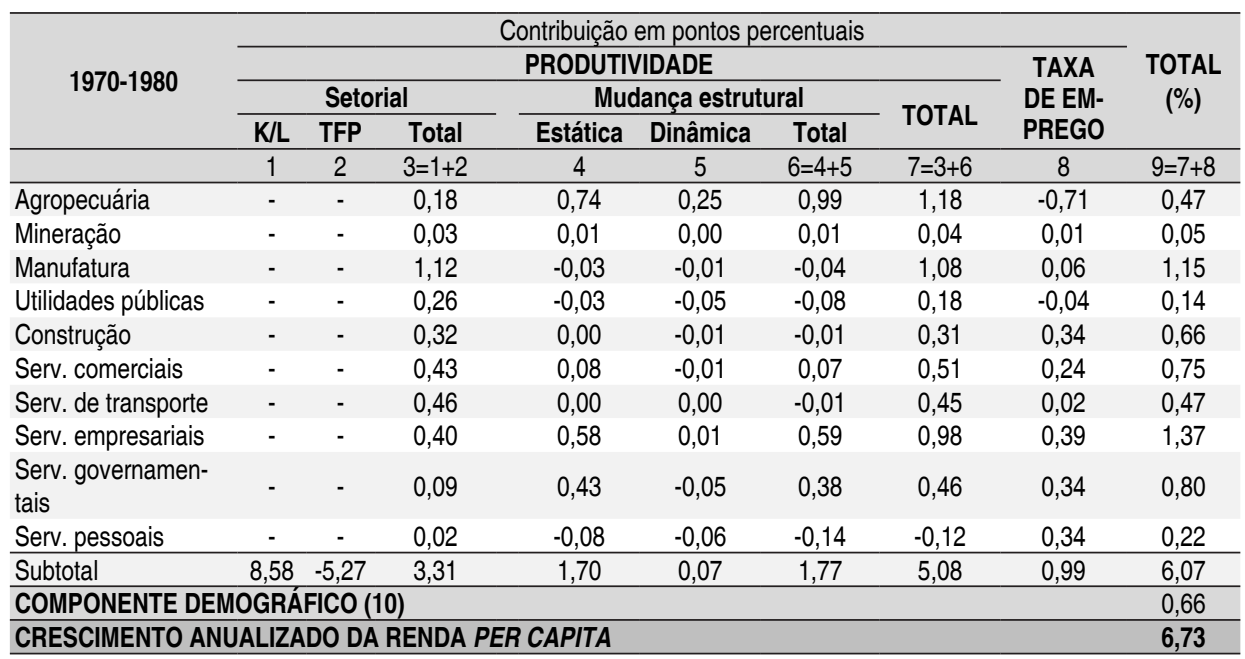

Fonte: Elaboração própria. Nota: a taxa de crescimento da renda per capita resulta da soma de 9 e 10.

\begin{tabular}{|c|c|c|c|c|c|c|c|c|c|}
\hline \multirow{4}{*}{$1980-1990$} & \multicolumn{8}{|c|}{ Contribuição em pontos percentuais } & \multirow{4}{*}{$\begin{array}{c}\text { TOTAL } \\
\text { (\%) }\end{array}$} \\
\hline & \multicolumn{7}{|c|}{ PRODUTIVIDADE } & \multirow{3}{*}{$\begin{array}{c}\text { TAXA } \\
\text { DE EM- } \\
\text { PREGO }\end{array}$} & \\
\hline & \multicolumn{3}{|c|}{ Setorial } & \multicolumn{3}{|c|}{ Mudança estrutural } & \multirow{2}{*}{ TOTAL } & & \\
\hline & $\mathrm{K} / \mathrm{L}$ & TFP & Total & Estática & Dinâmica & Total & & & \\
\hline & 1 & 2 & $3=1+2$ & 4 & 5 & $6=4+5$ & $7=3+6$ & 8 & $9=7+8$ \\
\hline Agropecuária & - & - & 0,13 & 1,15 & $-0,15$ & 1,00 & 1,13 & $-0,86$ & 0,27 \\
\hline Mineração & - & - & 0,06 & 0,00 & 0,00 & $-0,01$ & 0,05 & 0,00 & 0,06 \\
\hline Manufatura & - & - & $-1,02$ & 0,15 & $-0,05$ & 0,09 & $-0,93$ & 0,34 & $-0,59$ \\
\hline Utilidades públicas & - & - & 0,11 & $-0,03$ & $-0,01$ & $-0,04$ & 0,08 & 0,00 & 0,07 \\
\hline Construção & - & - & $-0,19$ & 0,01 & 0,00 & 0,01 & $-0,17$ & $-0,10$ & $-0,27$ \\
\hline Serv. comerciais & - & - & $-1,13$ & 0,26 & $-0,18$ & 0,08 & $-1,04$ & 0,71 & $-0,33$ \\
\hline Serv. de transporte & - & - & $-0,20$ & 0,08 & $-0,01$ & 0,07 & $-0,13$ & 0,10 & $-0,03$ \\
\hline Serv. empresariais & - & - & $-0,38$ & 0,07 & 0,00 & 0,06 & $-0,32$ & 0,12 & $-0,20$ \\
\hline $\begin{array}{l}\text { Serv. governamen- } \\
\text { tais }\end{array}$ & - & - & $-0,66$ & 0,27 & $-0,06$ & 0,21 & $-0,45$ & 0,34 & $-0,11$ \\
\hline Serv. pessoais & - & - & $-0,14$ & $-0,16$ & 0,01 & $-0,16$ & $-0,29$ & 0,35 & 0,05 \\
\hline Subtotal & $-7,08$ & 3,68 & $-3,41$ & 1,79 & $-0,45$ & 1,33 & $-2,08$ & 1,00 & $-1,08$ \\
\hline \multicolumn{9}{|c|}{ COMPONENTE DEMOGRÁFICO (10) } & 0,44 \\
\hline \multicolumn{9}{|c|}{ CRESCIMENTO ANUALIZADO DA RENDA PER CAPITA } & $-0,64$ \\
\hline
\end{tabular}

Fonte: Elaboração própria. Nota: a taxa de crescimento da renda per capita resulta da soma de 9 e 10. 


\begin{tabular}{|c|c|c|c|c|c|c|c|c|c|}
\hline \multirow{4}{*}{$1990-2000$} & \multicolumn{8}{|c|}{ Contribuição em pontos percentuais } & \multirow{4}{*}{$\begin{array}{c}\text { TOTAL } \\
(\%)\end{array}$} \\
\hline & \multicolumn{7}{|c|}{ PRODUTIVIDADE } & \multirow{3}{*}{$\begin{array}{c}\text { TAXA } \\
\text { DE EM- } \\
\text { PREGO }\end{array}$} & \\
\hline & \multicolumn{3}{|c|}{ Setorial } & \multicolumn{3}{|c|}{ Mudança estrutural } & \multirow{2}{*}{ TOTAL } & & \\
\hline & $\mathrm{K} / \mathrm{L}$ & TFP & Total & Estática & Dinâmica & Total & & & \\
\hline & 1 & 2 & $3=1+2$ & 4 & 5 & $6=4+5$ & $7=3+6$ & 8 & $9=7+8$ \\
\hline Agropecuária & - & - & 0,20 & 0,32 & $-0,01$ & 0,32 & 0,51 & $-0,71$ & $-0,20$ \\
\hline Mineração & - & - & 0,13 & $-0,06$ & $-0,03$ & $-0,09$ & 0,04 & $-0,02$ & 0,01 \\
\hline Manufatura & - & - & 0,65 & $-0,06$ & $-0,06$ & $-0,12$ & 0,54 & $-0,43$ & 0,10 \\
\hline Utilidades públicas & - & - & 0,26 & $-0,09$ & $-0,05$ & $-0,14$ & 0,12 & $-0,03$ & 0,09 \\
\hline Construção & - & - & 0,03 & 0,00 & 0,00 & 0,00 & 0,04 & $-0,12$ & $-0,08$ \\
\hline Serv. comerciais & - & - & $-0,08$ & $-0,06$ & $-0,01$ & $-0,07$ & $-0,15$ & 0,09 & $-0,06$ \\
\hline Serv. de transporte & - & - & 0,12 & 0,06 & 0,01 & 0,06 & 0,18 & 0,01 & 0,20 \\
\hline Serv. empresariais & - & - & $-0,81$ & 0,04 & $-0,01$ & 0,03 & $-0,78$ & $-0,08$ & $-0,86$ \\
\hline $\begin{array}{l}\text { Serv. governamen- } \\
\text { tais }\end{array}$ & - & - & 0,04 & 0,07 & 0,00 & 0,07 & 0,12 & $-0,03$ & 0,08 \\
\hline Serv. pessoais & - & - & 0,01 & $-0,14$ & 0,00 & $-0,15$ & $-0,14$ & 0,07 & $-0,06$ \\
\hline Subtotal & 1,04 & $-0,48$ & 0,56 & 0,09 & $-0,17$ & $-0,08$ & 0,48 & $-1,26$ & $-0,78$ \\
\hline \multicolumn{9}{|c|}{ COMPONENTE DEMOGRÁFICO (10) } & 0,69 \\
\hline \multicolumn{9}{|c|}{ CRESCIMENTO ANUALIZADO DA RENDA PER CAPITA } & $-0,09$ \\
\hline
\end{tabular}

Fonte: Elaboração própria. Nota: a taxa de crescimento da renda per capita resulta da soma de 9 e 10 .

\begin{tabular}{|c|c|c|c|c|c|c|c|c|c|}
\hline \multirow{4}{*}{ 2000-2010 } & \multicolumn{8}{|c|}{ Contribuição em pontos percentuais } & \multirow{4}{*}{$\begin{array}{c}\text { TOTAL } \\
(\%)\end{array}$} \\
\hline & \multicolumn{7}{|c|}{ PRODUTIVIDADE } & \multirow{3}{*}{$\begin{array}{l}\text { TAXA } \\
\text { DE EM- } \\
\text { PREGO }\end{array}$} & \\
\hline & \multicolumn{3}{|c|}{ Setorial } & \multicolumn{3}{|c|}{ Mudança estrutural } & \multirow{2}{*}{ TOTAL } & & \\
\hline & $\mathrm{K} / \mathrm{L}$ & TFP & Total & Estática & Dinâmica & Total & & & \\
\hline & 1 & 2 & $3=1+2$ & 4 & 5 & $6=4+5$ & $7=3+6$ & 8 & $9=7+8$ \\
\hline Agropecuária & - & - & 0,27 & 0,40 & $-0,01$ & 0,39 & 0,66 & $-0,42$ & 0,23 \\
\hline Mineração & - & - & 0,06 & 0,00 & 0,00 & 0,01 & 0,07 & 0,00 & 0,07 \\
\hline Manufatura & - & - & $-0,02$ & 0,01 & 0,00 & 0,00 & $-0,02$ & 0,10 & 0,08 \\
\hline Utilidades públicas & - & - & 0,07 & $-0,03$ & 0,00 & $-0,03$ & 0,04 & 0,00 & 0,04 \\
\hline Construção & - & - & $-0,04$ & $-0,01$ & $-0,01$ & $-0,01$ & $-0,06$ & 0,13 & 0,07 \\
\hline Serv. comerciais & - & - & 0,14 & $-0,03$ & 0,00 & $-0,03$ & 0,11 & 0,27 & 0,38 \\
\hline Serv. de transporte & - & - & $-0,18$ & 0,03 & $-0,01$ & 0,02 & $-0,15$ & 0,06 & $-0,09$ \\
\hline Serv. empresariais & - & - & 0,14 & 0,12 & 0,01 & 0,12 & 0,27 & 0,29 & 0,55 \\
\hline Serv. governamentais & - & - & 0,03 & 0,01 & 0,00 & 0,01 & 0,04 & 0,10 & 0,14 \\
\hline Serv. pessoais & - & - & 0,01 & $-0,07$ & 0,00 & $-0,07$ & $-0,06$ & 0,20 & 0,14 \\
\hline Subtotal & $-2,38$ & 2,87 & 0,48 & 0,44 & $-0,03$ & 0,41 & 0,89 & 0,73 & 1,62 \\
\hline \multicolumn{9}{|c|}{ COMPONENTE DEMOGRÁFICO (10) } & 0,54 \\
\hline \multicolumn{9}{|c|}{ CRESCIMENTO ANUALIZADO DA RENDA PER CAPITA } & 2,16 \\
\hline
\end{tabular}

Fonte: elaboração própria. Nota: a taxa de crescimento da renda per capita resulta da soma de 9 e 10. 